\title{
Path Optimization Model for Intra-City Express Delivery in Combination with Subway System and Ground Transportation
}

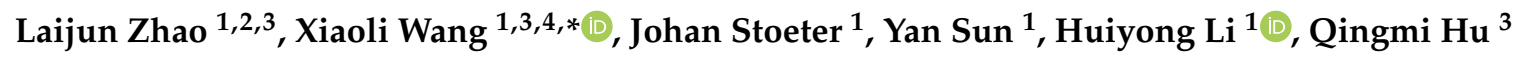 \\ and Meichen $\mathrm{Li}^{1}$ \\ 1 Sino-US Global Logistics Institute, Shanghai Jiao Tong University, Shanghai 200030, China; \\ ljzhao70@sjtu.edu.cn (L.Z.); Johan1992@sjtu.edu.cn (J.S.); sunyan66@126.com (Y.S.); hyl_shu@163.com (H.L.); \\ happy_lmc@163.com (M.L.) \\ 2 China Institute for Urban Governance, Shanghai Jiao Tong University, Shanghai 200030, China \\ 3 Antai College of Economics \& Management, Shanghai Jiao Tong University, Shanghai 200030, China; \\ qingmihu@sjtu.edu.cn \\ 4 School of Management, Shanghai University of Engineering Science, Shanghai 200030, China \\ * Correspondence: wxl-0539@163.com; Tel.: +86-021-6787-4149
}

Received: 25 November 2018; Accepted: 20 January 2019; Published: 1 February 2019

\begin{abstract}
Combined conventional ground transport with a subway system for line-haul transport for intra-city express delivery is a new transportation mode. Subway transportation can be used in the line-haul transportation of intra-city express delivery services to reduce cost, improve efficiency, raise customer satisfaction, and alleviate road congestion and air pollution. To achieve this, we developed a path optimization model (POM) with time windows for intra-city express delivery, which makes use of the subway system. Our model integrated the subway system with ground transportation in order to minimize the total delivery time. It considered the time window requirements of the senders and the recipients, and was constrained by the frequency of trains on the subway line. To solve the $\mathrm{POM}$, we designed a genetic algorithm. The model was tested in a case study of a courier company in Shanghai, China. Meanwhile, based on the basic scenario, the corresponding solutions of the four different scenarios of the model are carried out. Then, we further analyzed the influence of the number of vehicles, the frequency of trains on the subway line, and the client delivery time window on the total delivery time, client time window satisfaction, and courier company costs based on the basic scenario. The results demonstrated that the total delivery time and the total time outside the time window decreased as the number of vehicles increased; the total delivery time and the total time outside the time window decreased as the delivery frequency along the subway line increased; the total delivery time and the total time outside the time window decreased as the sender's time window increased. However, when the sender's time window increased beyond a certain threshold, the total delivery time and the total time outside the time window no longer decreased greatly. The case study results can guide courier companies in path optimization for intra-city express delivery vehicles in combination with the subway network.
\end{abstract}

Keywords: intra-city express delivery; underground logistic system; subway system; path optimization; genetic algorithm

\section{Introduction}

"Intra-city delivery" refers to the express delivery of products from point A to point B within the same city. The business activities and the personal activity within a city has caused the demand for "door to door" distribution express to increase, so intra-city express deliveries will continue to increase, 
especially driven by the internet's ability to permit instant ordering of products. Thus, intra-city express delivery will become one of the most frequent logistics activities.

The delivery distance for intra-city express delivery is relatively short [1]. The characteristics of the delivered goods determine the need for high efficiency. For example, business documents and local packages must typically be delivered within the same day, whereas fresh food must be delivered within hours. As a result, the courier companies need to continue to introduce increasingly punctual and fast delivery services, so that recipients can receive goods quickly and within a precise time period.

Current intra-city express delivery is mainly performed by electric vehicles and small to medium gas-powered vehicles. The timeliness of this distribution delivery is easily affected by factors such as traffic congestion and bad weather (e.g., rain and snow). Where electric vehicles are not yet widely used, the distribution delivery can also lead to air pollution problems and a potential safety hazard to pedestrians [2-4]. Barceló et al. [5] proposed that urban distribution through a city's underground logistics system could effectively solve these problems. Kikuta et al. [6] proposed the adoption of a new urban logistics system that combines the public subway service with traditional ground transport to alleviate urban traffic congestion, air pollution, and delivery delays.

Underground logistic systems have been studied for almost 30 years. Britain [7], Japan [8], and the Netherlands [9] have explored various combinations of underground logistics, but their efforts have failed due to high construction and operating costs, economic risks, and vague and missing of investors, etc. For example, the underground logistics system of London, England, which was used to transport mail from 1927 to 2006, was terminated due to a lack of economic support from the government. Development of Netherlands' underground logistics system, which began in 1997 and was planned to be connected to Amsterdam's Schiphol airport, the Aalsmeer flower market, and Hoofddorp subway station, was shelved in 2002 due to the lack of financial support. As research has progressed, the feasibility and mode of an underground logistics system based on subway networks has become a hot topic of discussion and research [1]. Particular emphasis has been placed on using the existing subway network and other components of the underground logistics system. Due to the high cost and long construction periods for new underground corridors, attention has shifted towards the existing subway network, which is relatively mature and developed, and has surplus capacity, particularly during off-peak hours. The subway network offers the advantages of fast speed, punctuality, safety, accessibility, and high carrying capacity, suggesting that this system can meet the growing demand and the high timeliness requirement of intra-city express delivery.

According to the China Vehicle Environmental Management Annual Report (2018), the energy consumption and pollutant emission $\left(\mathrm{CO}_{2}\right)$ of railway transportation per unit $(\mathrm{t}-\mathrm{km})$ are only one-seventh and one-thirteenth of highway transportation. Subways are closed-off railway systems which use electricity for propulsion and often operate underground, which further reduces air pollution. An underground logistics system based on the existing subway network can also support the development of a resource-saving society and sustainable development of cities, as it greatly reduces fuel consumption and pollutant emission compared with conventional ground transport (i.e., gas-powered vehicles). Many innovative courier companies of inter-city express delivery have used the existing subway network to deliver packages in Shanghai, but these companies have certain disadvantages, such as low delivery efficiency, high delivery cost, and unstable delivery timeliness. The main problem in the operation of courier services is the lack of planning and design of an optimal logistics network. Furthermore, intra-city courier companies suffer from high delivery cost and low delivery efficiency, and cause road congestion and air pollution with their delivery vehicles. A decision-support model for courier companies can guarantee timely delivery, reduce the delivery cost and, in combination with the subway network, alleviate the congestion and pollution problems. Therefore, we set up a new model for express vehicle path optimization with time windows.

In this paper, we build a model that can be used to optimize path of intra-city express delivery. In this model, line-haul transportation within the city is completed using the subway system, and the pickup and delivery links are completed by conventional ground vehicles. The remainder of the paper 
is organized as follows. In Section 2, we review the literature in this area of research. In Section 3, we develop an intra-city express delivery POM with the time window constraint of the senders and the recipients, and design a genetic algorithm to solve the model. In Section 4, based on data from a real courier company in Shanghai, China, we conduct an empirical study of the model. Meanwhile, according to the actual problem encountered in the delivery of courier companies, based on the basic scenario, the corresponding solutions of the four different scenarios of the model are carried out. Then, we explore the influence of the number of vehicles, the delivery frequency along the subway line, and the client time window on the total delivery time, satisfaction with client time window, and the courier company cost based on the basic scenario. Based on this analysis, we discuss optimization of the system. In Section 5, we conclude with a summary of our key results and provide suggestions for future research.

\section{Literature Review}

An underground logistic system refers to a system for transporting and supplying goods by connecting major underground freight stations (collection and distribution hubs) through tunnels or pipelines. The logistics components of this system include a traditional pipeline transportation of liquids, such as oil and gases such as natural gas, and the transportation of goods in a broad sense (e.g., packages). The literature on these systems has focused on theoretical research related to the concept and its feasibility. Sinfield and Einstein [10] demonstrated the feasibility of a pipeline transportation system through cost analysis. Stein and Schoesser [11] designed a conceptual model of the CargoCap system (http:/ / www.cargocap.com/). Roop et al. [12] investigated the technical and economic feasibility of using a freight-conveying pipeline to reduce highway truck traffic on I-35 in Texas, USA. Liu [13] assessed the technical and economic feasibility of using pipelines for inflatable capsules to transport goods belowground in New York City. Qian [14] proposed that an underground logistics system could be applied to solve the traffic problems of large cities by reducing the number of vehicles on the road, and analyzed the feasibility of the scheme in light of the actual situation in Beijing.

As the research progressed, some scholars studied the logistics business using urban subway and existing rail transit networks. For example, He et al. [1] proposed a new urban logistics delivery system based on Rail Transit. Kikuta et al. [6] studied the subway system in Sapporo of Japan and found that integrating the traditional truck transportation system with the subway made the distribution of goods between the suburbs and downtown smoother. Dampier et al. [15] studied the feasibility and potential problems of direct transportation of goods to the urban center of Newcastle in England, using the Tyne-Wear subway system. As urbanization progresses, traffic congestion and environmental pollution increase, and land constraints become increasingly serious, resulting in the use of the existing rail network in an underground logistics system having gradually moved from theory to experiment, and even to implementation. Since 2004, the Cargo-Tram system in Zürich, Switzerland, has been using the public rail network to pick up and transport large pieces of garbage [16]. Since 2007, CityCargo trams in Amsterdam, Netherlands, have been allowed to run after passenger trains on some routes of the existing urban rail network to transport goods to downtown malls, supermarkets, and restaurants. In 2016, Yamato Transportation, a joint logistics giant, began to use freight cars on the Tokyo subway's Yurakucho line to test express delivery using subway trains. Although the results have not yet been analyzed, the move is expected to ease road congestion, reduce pollutant emissions, and address a shortage of truck drivers. Previous research has promoted the development of underground logistical systems, but research and practice are still in the initial stages. There is a lack of studies on the combination of underground logistical systems and other logistics modes. Research on logistical systems incorporating subway networks is still in the stage of small-scale exploration and mainly focuses on its feasibility and implementation. There are only a few quantitative studies on network planning in this field.

At present, intra-city distribution services rely on traditional distribution modes (i.e., primarily ground vehicles), but have begun to incorporate the "Internet+" distribution mode and underground 
logistics model. The rapid development of online-to-offline commerce has created diverse intra-city distribution demands. This diversity requires different delivery times, different packaging, and different loading requirements, thus increasing the complexity of distribution and service requirements. Future distribution demand will be even more diversified because clients have strict requirements for intra-city express delivery. Liao [17] studied the intra-city distribution network of EMS Courier in Wuhan, China, by combining data envelopment analysis and vehicle routing problem models. Barceló et al. [5] studied a model of vehicle path and scheduling in a distribution network. He et al. [18] studied the advantages of using the surplus capacity of Beijing's subway network for intra-city delivery. Song and Cui [19] used an improved genetic algorithm model to solve the optimization problem of intra-city distribution paths with the goal of finding the shortest total distance. Guo et al. [20] used a multi-layer ant-colony algorithm for the path selection problem by considering cost and time in the express delivery network. There is abundant research on parcel distribution, but the research on incorporating subway networks into intra-city parcel distribution is still at an exploratory stage. Some studies performed small-scale tests. There are few studies on the optimization of the operations strategy, distribution network, and distribution path, and the integration of subway networks into intra-city express delivery.

Since ground transportation is completed by vehicles in intra-city express delivery based on the subway network, vehicle path planning is an important component of path planning. Many scholars have studied vehicle path planning (VRP). Dantzig and Ramser [21] first proposed the concept of VRP. Balinski and Quandt [22] solved a relatively simple VRP problem by using a cutting-plane algorithm. Clarke and Wright [23] developed the Clarke-Wright algorithm to solve the VRP problem with a variable number of vehicles. Eilon et al. [24] applied dynamic programming to solve a VRP problem with 50 points. Laporte et al. [25] pioneered the use of branch-bounded algorithms to solve classical VRP problems. Perboli et al. [26] studied the two-echelon capacitated vehicle routing problem and solved it using math-based heuristics. As research has progressed, researchers have incorporated the concept of time window by adding the delivery time window requirements (soft, hard, and mixed time windows) to the classic VRP problem. Vidal et al. [27] designed a hybrid genetic algorithm for solving large-scale time-constrained VRP problems. Hou et al. [28] studied optimization of vehicle logistics distribution paths with soft time window by using an adaptive genetic algorithm. Ghilas et al. [29] studied the delivery problem with fixed reservation lines to account for time windows and solved the problem with a large-scale neighborhood search algorithm. Wei et al. [30] designed a competitive decision algorithm based on a time threshold to solve the VRP problem with a time constraint. VRP is a well-researched class of problems. Most of the studies focus on dynamic strategies and re-optimization algorithms. At present, only a few articles combine subway transportation with path optimization of road transportation for distribution problems. Most studies concentrate on the path optimization of inter-city logistics distribution centers and distribution points. Only few studies consider the vehicle path optimization for intra-city express delivery in combination with the subway network. Previous research on using subway as the main line transportation mode was also limited to feasibility studies and qualitative suggestions.

\section{Building a POM of Intra-City Express Delivery with Time Window Constraint}

Based on our previous research [31], we defined two intra-city delivery hubs, represented by two subway stations that were selected as collection and distribution hubs to connect the ground and underground logistics. This resulted in a complete system with three stages of express delivery: transport of goods by means of conventional ground transportation to a subway station that acts as a collection hub, followed by transport along a subway line to a subway station that acts as a distribution hub, and concluding with delivery using conventional ground transport. Figure 1 illustrates this system. Each collection hub covers a certain range of senders. Each distribution hub covers a certain range of recipients. There is room for optimization in the whole delivery process. When a sender places a sending order, the courier from a collection hub shall be sent to pick up the goods and then return 
them to the collection hub. Within the process, the senders have the requirement of time window. Then, the goods in the collection hubs are transferred to a distribution hub through the subway line. Within the process, there is a limit of the delivery frequency along the subway line, so there may be a wait time for each batch of packages in the collection hub. The packages are transferred to a subway train and transported along a subway line. Within the process, the transportation of packages is subject to the delivery frequency along the subway line. Lastly, when the goods reach the distribution hubs, they are delivered to the recipients by couriers. Within the process, recipients also have the time window requirements.

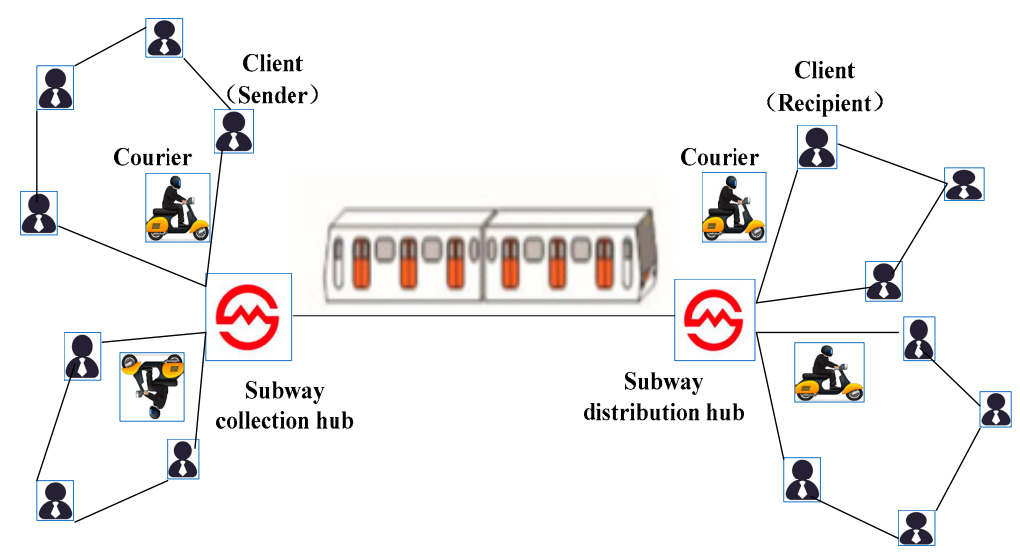

Figure 1. Illustration of an intra-city express delivery system in combination with subway system and conventional ground transportation.

\subsection{Model Development}

In this section, based on the three stages of the delivery system in Figure 1, and having met the requirements of both senders and recipients for delivery time windows, we established a POM with the goal of minimum total delivery time and designed the solution algorithm.

\section{(1) Model assumptions}

- All recipients' and senders' needs are known.

- We consider only express delivery between the collection hub and the distribution hub.

- The collection hub is only responsible for collecting packages from senders. The distribution hub is only responsible for the distribution of packages to recipients.

- The distance from the senders to the collection hub and the distance from the distribution hub to the recipients are both no more than half the maximum mileage of delivery vehicles.

- The same vehicles are used throughout the ground network.

- Each collection hub covers a certain range of senders. Each distribution hub covers a certain range of recipients.

\section{(2) Parameter definition}

$i$ : senders who use the system to distribute their packages ( $i=1$ to $N ; i=0$ represents the collection hub).

$j$ : sender who use the system to distribute their packages $(j=1$ to $N ; j=0$ represents the collection hub).

$i^{\prime}$ : recipients who use the system to receive their packages $\left(i^{\prime}=1\right.$ to $M ; i^{\prime}=0$ represents the distribution hub).

$j^{\prime}$ : recipients who use the system to receive their packages $\left(j^{\prime}=1\right.$ to $M ; j^{\prime}=0$ represents the distribution hub).

$\left(i, i^{\prime}\right)$ : the combination of a sender and recipient. 
$k$ : the vehicles used to pick up packages from senders $(k=1$ to $P)$.

$k^{\prime}$ : the vehicles used to deliver packages to the recipients $\left(k^{\prime}=1\right.$ to $\left.Q\right)$

$q_{\text {max }}$ : the maximum load capacity of the vehicles.

$q_{i}$ : the volume of sanders' packages.

$q_{i^{\prime}}$ : the volume of recipients' packages.

$t_{i, j}$ the transportation time between points $i$ and $j$.

$\left[E_{i}, L_{i}\right]$ : the delivery time window requirement (earliest and latest times, respectively) for client $i$

$L_{i^{\prime}}$ : the latest time when client $i^{\prime}$ must receive their packages.

$D T_{n}$ : the time of the $n$-th delivery along the subway line $(n=1$ to $W)$.

$t w_{k}$ : the waiting time of packages collected by the vehicle $k$ in the collection hub.

$t_{\mathrm{m}}$ : the transportation time of along the subway line between the collection hub and the distribution hub.

$t w_{i^{\prime}}$ : the waiting time of each packages before delivery in the distribution hub.

$S_{k}$ : the time when vehicles from the collection hub start to pick up packages.

$S_{k^{\prime}}$ : the time when vehicles from the distribution hub start to distribution packages.

$T_{i}$ : the time when vehicles arrive at client $i$.

\section{(3) Decision variables}

We used the following decision variables:

$x_{i j k}=1$ when vehicle $k$ travels from client $i$ to client $j$, or 0 otherwise.

$y_{k i}=1$ when a package from client $i$ is delivered by vehicle $k$, or 0 otherwise.

$z_{k n}=1$ when vehicle $k$ arrives at the distribution hub at a time between DTn and DTn +1 , or 0 otherwise.

\section{(4) Objective function}

$$
\min Z=\sum_{i=0}^{N} \sum_{j=0}^{N} \sum_{k=0}^{P} x_{i j k} t_{i j}+\sum_{i=0}^{N} \sum_{k=0}^{M} y_{k i} t w_{k}+N \times t m+\sum_{i^{\prime}=0}^{M} t w_{i^{\prime}}+\sum_{i^{\prime}=0}^{M} \sum_{j^{\prime}=0}^{M} \sum_{k^{\prime}=0}^{Q} y_{k^{\prime} i^{\prime}} x_{i^{\prime} j^{\prime} k^{\prime}} t_{i^{\prime} j^{\prime}}
$$

Equation (1) represents the objective function, which is designed to minimize the total delivery time. $\sum_{i=0}^{N} \sum_{j=0}^{N} \sum_{k=0}^{P} x_{i j k} t_{i j}$ represents the total time for collecting all packages; $\sum_{i=0}^{N} \sum_{k=0}^{M} y_{k i} t w_{k}$ indicates the total time that all packages are waiting for transportation in the collection hub. $N \times t m$ indicates transportation time of all packages along the subway line; $\sum_{i^{\prime}=0}^{M} t w_{i^{\prime}}$ indicates the total time for all packages waiting in the distribution hub; and $\sum_{i^{\prime}=0}^{M} \sum_{j^{\prime}=0}^{M} \sum_{k^{\prime}=0}^{Q} y_{k^{\prime} i^{\prime}} x_{i^{\prime} j^{\prime} k^{\prime}} t_{i^{\prime} j^{\prime}}$ represents the total time of distribution all packages.

\section{(5) Constraint conditions}

$$
\begin{gathered}
\sum_{i=1}^{N} q_{i} y_{k i} \leq q_{\max } \quad \forall k \\
\sum_{i^{\prime}=1}^{M} q_{i^{\prime}} y_{k^{\prime} i^{\prime}} \leq q_{\max } \quad \forall k^{\prime}
\end{gathered}
$$

Equations (2) and (3) represent the capacity limit for each vehicle. In other words, the volume of packages in a vehicle cannot exceed the vehicle's capacity.

$$
\sum_{k=1}^{P} y_{k i}=1 \quad \forall i
$$




$$
\sum_{k^{\prime}=1}^{Q} y_{k^{\prime} i^{\prime}}=1 \quad \forall i^{\prime}
$$

Equations (4) and (5) indicate that each client has only one vehicle for the delivery service.

$$
\begin{gathered}
\sum_{j=1}^{N} x_{i j k}=y_{k i} \quad \forall k \quad \forall i \\
\sum_{j^{\prime}=1}^{M} x_{i^{\prime} j^{\prime} k^{\prime}}=y_{k^{\prime} i^{\prime}} \quad \forall k^{\prime} \quad \forall i^{\prime}
\end{gathered}
$$

Equation (6) indicates that vehicle $\mathrm{k}$ service for a sender $i$, and Equation (7) indicates that vehicle $k^{\prime}$ service for a recipients' $i^{\prime}$. After the task is completed, the vehicle must leave that the client.

$$
\begin{gathered}
\sum_{i=1}^{N} x_{i j k}=y_{k j} \quad \forall k \quad \forall j \\
\sum_{i^{\prime}=1}^{M} x_{i^{\prime} j^{\prime} k^{\prime}}=y_{k^{\prime} j^{\prime}} \quad \forall k^{\prime} \quad \forall j^{\prime}
\end{gathered}
$$

Equation (8) indicates that every vehicle arriving at point $j$ will provide a service to that point. Equation (9) indicates that every vehicle arriving at point $j^{\prime}$ will provide a service to that point.

$$
\begin{gathered}
\sum_{j=1}^{N} x_{0 j k}=1 \quad \forall k \\
\sum_{j^{\prime}=1}^{M} x_{0 j^{\prime} k^{\prime}}=1 \quad \forall k^{\prime}
\end{gathered}
$$

Equations (10) and (11) indicate, respectively, that each vehicle starts from the collection hub and the distribution hub.

$$
\begin{gathered}
\sum_{i=1}^{N} x_{i 0 k}=1 \quad \forall k \\
\sum_{i^{\prime}=1}^{M} x_{i^{\prime} 0 k^{\prime}}=1 \quad \forall k^{\prime}
\end{gathered}
$$

Equations (12) and (13) indicate respectively that each vehicle eventually returns to the collection hub and the distribution hub.

$$
\sum_{i \in U_{k}, j \notin U_{k}}^{N} x_{i j k}=1 \quad U_{k}=\left\{i \mid y_{k i}=1\right\} \quad \forall k
$$

Equation (14) indicates that there is only one loop in the path of each vehicle; that is, the vehicle does not travel over the same path twice before it returns to the subway delivery hub.

$$
\begin{gathered}
T_{i}=y_{k i} S_{k}+\sum_{i^{\prime}=0}^{M} \sum_{j^{\prime}=0}^{M} t_{i^{\prime} j^{\prime}} \quad \forall k \\
E_{i} \leq T_{i} \leq L_{i} \quad \forall i
\end{gathered}
$$

Equations (15) and (16) indicate that the courier must pick up the package within the sender time window.

$$
t_{w k}=\sum_{n=1}^{W} z_{k n} D T_{n}-\left(S_{k}+\sum_{i=0}^{N} \sum_{j=0}^{N} x_{i j k} t_{i j}\right) \quad \forall k
$$




$$
\begin{gathered}
\sum_{n=1}^{W} z_{k n}=1 \quad \forall k \\
t_{w k} \geq 0
\end{gathered}
$$

Equation (17) represents the waiting time of each vehicle in the collection hub. Equation (18) indicates that the variables have a value of 0 or 1 . Equation (19) indicates that the waiting time is greater than or equal to 0 .

$$
\begin{gathered}
y_{k^{\prime} i^{\prime}}=z_{k n} y_{k i} \\
t w_{i^{\prime}}=y_{k^{\prime} i^{\prime}} S_{k^{\prime}}-\left(\sum_{k=1}^{P} \sum_{n=1}^{W} y_{k^{\prime} i^{\prime}} D T_{n+1}+t m\right) \quad \forall k^{\prime}
\end{gathered}
$$

Equations (20) and (21) describe the waiting time of each package in the distribution hub.

$$
\begin{gathered}
T_{i^{\prime}}=y_{k^{\prime} i^{\prime}} S_{k^{\prime}}+\sum_{i^{\prime}=0}^{M} \sum_{j^{\prime}=0}^{M} t_{i^{\prime} j^{\prime}} \quad \forall k^{\prime} \\
T_{i^{\prime}} \leq L_{i^{\prime}} \quad \forall i^{\prime}
\end{gathered}
$$

Equations (22) and (23) indicate that the courier must complete the delivery before the latest delivery time required by the recipient.

$$
\begin{array}{cc}
x_{i j k} \in\{0,1\} \quad \forall i, j, k \\
y_{k i} \in\{0,1\} \quad \forall k, i \\
z_{k n} \in\{0,1\} \quad \forall k, n
\end{array}
$$

Equations (24) to (25) indicate that each variable has a value of 0 or 1.

\subsection{Genetic Algorithm Design}

In this section, we describe a POM that adds strict time window constraints to the classical VRP model and that contains nonlinear constraints. The genetic algorithm is quite mature, and it has been demonstrated that it can be used to solve many path planning problems. The basic idea of a genetic algorithm is to encode decision variables and then use global search to get the global optimal solution. Genetic algorithms are not dependent on function derivability and robustness. In this context, we designed an improved genetic algorithm suitable for embedding heuristic rules and a double-layer chromosome coding to solve the optimization problem. The implementation steps of the algorithm are as follows.

\section{(1) Coding}

In the model, the final decision is the delivery path for each vehicle, so chromosome coding is an array with a nonrepeat arrangement that contains all senders and recipients. We used natural number coding rules. Path segmentation requires that the total volume of the packages delivered by each vehicle cannot exceed the vehicle's standard load capacity. According to the order, from left to right, the sequence of client points reaching vehicle load is determined as a vehicle path. For example, using 0 represents the distribution hub. The nine clients are numbered 1-9. For example, if we assume that there are 3 vehicles in a transfer center, if the loading capacity is satisfied, the initial code can be written as 0123045607890 , which represents that the first vehicle starts from a collection hub, first goes to client 1 to pick up the packages, then to client 2 to pick up the packages, then to client 3 to pick up the packages, and finally returns to the collection hub, and so on.

\section{(2) Population Initialization}

According to the rules for seed coding, a large number of seeds are randomly generated to form the initial population. The population size directly affects the computational efficiency and rate of 
convergence of the genetic algorithm. Since there are both senders and recipients in this problem, we used double-chromosome coding (i.e., one chromosome for senders and another one for recipients) during population initialization.

Initialization of the upper chromosome: The upper chromosome represents the path the vehicle travels to pick up packages from senders. To improve the algorithm's efficiency, we embedded a time window sort heuristic rule. We assumed that the sender's point, with a larger upper bound for their pickup time window $\left(L T_{\mathrm{n}}\right)$, can have its pickup task postponed temporarily. Therefore, the pickup order for each vehicle is sorted from the sender with the shortest pickup time window to the sender with the longest pickup time window, with the goal of generating a better initial population.

Initialization of the lower chromosome: The lower chromosome represents the path the vehicle travels do deliver packages to recipients. There is a logical correspondence between the lower chromosome and the upper chromosome because the delivery schedule cannot begin until the pickup schedule is complete. We took the following four steps for the encoding and initialization:

Step 1: We set the natural number code of the lower chromosome to the same value as for the upper chromosome. For example, if the upper chromosome encoding adopted the natural numbers from 0 to 9 , the lower chromosome encoding adopted the same range.

Step 2: The initialization of the lower chromosome also adopted the time window heuristic rule. The bigger the delivery time window, the lower the client ranking (i.e., recipients with narrow delivery time windows received priority).

Step 3: We then checked the starting time for each dispatch path. If the starting time was after the arrival time at a certain point on the path, we defined that point as illegal.

Step 4: Illegality repair. We exchanged the illegal points with the last element on the chromosome and repeated the inspection in Step 3. If there was still at least one illegal point, we swapped those points with the second-to-last element on the chromosome. We repeated this process until no illegal points remained or all elements had been swapped.

\section{(3) Selection Operation}

In the selection process, the delivery time window constraints must be checked on each chromosome. Using an elimination strategy to eliminate unfeasible solutions will greatly reduce the search space and make it easier to identify the local optimal solution. Therefore, we used a penalty function to obtain the optimal solution that satisfies the delivery time window constraint.

The model's objective function is $f(x)$. The penalty function for outside the time window is $g(x)=t_{\mathrm{e}} f_{\mathrm{e}}+t_{1} f_{1}$, where $t_{\mathrm{e}}$ indicates the total time of arrival before the specified time window, $f_{\mathrm{e}}$ indicates the unit penalty cost if the courier must wait to pick up a package, $t_{1}$ indicates the time of arrival after the specified window, and $f_{1}$ indicates the unit penalty cost of the client waiting. The penalty function for a late delivery is $F(x)=f(x)+g(x)$. As the number of iterations increases, solutions that do not conform to the time window constraints are gradually eliminated from the set of possible solutions by the penalty function. After a large number of iterations, the penalty value for the window is much higher than the delivery cost, so all solutions that do not conform to the window constraint will be eliminated.

We also constructed a fitness function. The penalty function $F 1(x)$ that is used in the construction of the fitness function (Fit) is the minimum function, and it is transformed as follows:

$$
\operatorname{Fit}(F 1(x))= \begin{cases}C_{\max }-F 1(x), & F 1(x)<C_{\max } \\ 0 & \text { otherwise }\end{cases}
$$

The first $50 \%$ is reserved and the second $50 \%$ is crossed. We used the roulette wheel selection method in this analysis:

Step 1: We added the fitness value of the current population (i.e., the total Sum), which represents the total area of the roulette wheel.

Step 2: We generated random numbers in the interval [0,1], which we called "Rand". 
Step 3: We multiplied Rand by the total Sum to get a value between 0 and the total Sum, which is called the rotation wheel value. This value is the distance that the imaginary ball has traveled before it falls into a slot in the wheel.

Step 4: We checked the fitness value of an individual in a cumulative group until the cumulative fitness value of an individual was greater than or equal to the rotation wheel value, and then selected the individual.

\section{(4) Interlace operation}

If the sequentially encoded chromosome is crossed with the other chromosome using the traditional crossover operation, the crossed offspring are most likely to be in an illegal state, such as having two identical non-zero digits in the encoding. Hence, it was necessary to repair the chromosome to eliminate illegal values; to do so, we used loop crossover. Let the parent chromosomes be $P_{1}$ and $P_{2}$, and the offspring be $C_{1}$ and $C_{2}$. The specific steps are as follows:

Step 1: All zeroes in the parent chromosome are removed.

Step 2: The first element of $P_{1}$ is selected as the first element of $C_{1}$, and the first element of $P_{2}$ is selected as the first element of $C_{2}$.

Step 3: The first element of $P_{2}$ in $P_{1}$ is found and is assigned to the same relative position in $C_{1}$. This process is repeated until the first element of $P_{1}$ that is present in $P_{2}$. This is called a loop.

Step 4: Steps 2 to 3 are repeated for the former gene according to the principle of $P_{1}, P_{2}$ gene replacement.

Step 5: Repeat steps 1 to 4 until all the bits are completed.

\section{(5) Mutation operation}

Using the method of transposition variation, two gene positions are randomly selected on each chromosome to exchange the bit numbers of genes. After completion of this operation, we followed the cargo quantity constraint and added a 0 code into the chromosome to form a complete descendant code.

(6) Recalculate the fitness and repeat steps (3) to (5).

(7) The number of iterations is pre-set. When the algorithm has performed this number of iterations, it stops. The final result is obtained at this point.

\section{Empirical Case Study: Path Optimization for a Courier Company in Shanghai}

With the continuous development of the underground logistics systems, more and more courier companies will begin to use the subway network to make intra-city express deliveries. As a result, part of the traffic is transferred from road transportation to subway transportation. Subway networks have the advantages of wide coverage, timeliness, high efficiency, high frequency, and highly stable service, which helps courier companies to improve the timeliness of distribution and raise customer satisfaction. Important side effects are reduced road congestion, air pollution, and traffic accidents. In 2012, the Chinese E-commerce platform JD.com cooperated with the Beijing subway to provide self-pick-up service in 20 subway stations for deliveries that came via subway. In the same year, courier companies in Guangzhou began to test express delivery via subway. Since 2014, many small and medium-sized intra-city courier companies in Shanghai have used the subway network to make deliveries on trunk lines, such as "KSUDi Company", "East Union Express Company", and others. In order to solve the problems of intra-city express delivery, like single delivery mode, high cost, and low efficiency, this section applies our model to the customer data of an intra-city courier company in Shanghai. The results of this case study can provide guidance for courier companies planning to use subway transportation to optimize their intra-city express delivery vehicle paths. 


\subsection{Data Acquisition}

To demonstrate the use of our model, we obtained actual operational data from an intra-city courier company in Shanghai. To protect the company's confidentiality, we have not named them in this paper. We focused on a single delivery path between senders in People's Square and receivers in Longyang Road station along Line 2 of Shanghai subway, and obtained operational data from 1 June 2017. The data included each sender's geographic coordinates, package volume shipped, and delivery time window; and each recipient's geographic coordinates, package volume received, and delivery time window. We defined the relative coordinates of the People's Square subway station (the collection hub) and the Longyang Road subway station (the distribution hub) as $(5,0)$ and $(50,0)$, respectively. The transportation time along the subway line between the collection hub and the distribution hub is $0.5 \mathrm{~h}$. The delivery frequency interval along the subway line is 1 hour. If, in a certain delivery frequency along the subway line, there are no packages going to the collection hub, the delivery frequency along the subway line does not start. We defined the distance between client points as a European-style distance. For each package, there was a one-to-one correspondence between the sender's package number and the recipient's package number. The recipient's package number was defined as the corresponding sender's package number plus 20. The standard load capacity for the delivery vehicles was defined as $0.5 \mathrm{~m}^{3}$, which represents the capacity of the typical electric scooter that is used to deliver packages in Shanghai. The travel speed was $20 \mathrm{~km} / \mathrm{h}$. Table 1 summarizes the raw data used in the calculations.

Table 1. Sender and recipient locations, time windows, and volume of the package.

\begin{tabular}{ccccccc}
\hline & Sender & & Package & & Recipient & Package \\
Package & Coordinates & $\begin{array}{c}\text { Time } \\
\text { Wumber }\end{array}$ & Volume & $\begin{array}{c}\text { Toordinates } \\
\text { Number }\end{array}$ & $\begin{array}{c}\text { Time } \\
\text { Window }\end{array}$ \\
\hline 1 & $(-1.3,-5.3)$ & $(8,11)$ & 0.08 & 21 & $(40,-1.4)$ & $(-, 16)$ \\
2 & $(-10.4,-3.5)$ & $(11,13)$ & 0.13 & 22 & $(41,-5.5)$ & $(-, 17)$ \\
3 & $(-11.4,14)$ & $(9,12)$ & 0.05 & 23 & $(50,-4.7)$ & $(-, 16)$ \\
4 & $(9.6,-15.7)$ & $(12,14)$ & 0.16 & 24 & $(65,-5.8)$ & $(-, 18)$ \\
5 & $(-12.2,-10)$ & $(10,15)$ & 0.08 & 25 & $(52,11.6)$ & $(-, 18)$ \\
6 & $(-7.9,2.7)$ & $(9,11)$ & 0.06 & 26 & $(56.3,5.3)$ & $(-, 17)$ \\
7 & $(-5,-11.6)$ & $(8,10)$ & 0.10 & 27 & $(56.5,13.7)$ & $(-, 14)$ \\
8 & $(13,-7.6)$ & $(10,14)$ & 0.13 & 28 & $(50.4,18.9)$ & $(-, 17)$ \\
9 & $(15.4,9.9)$ & $(12,14)$ & 0.15 & 29 & $(48.2,-21)$ & $(-, 16)$ \\
10 & $(-7.8,-14)$ & $(12,15)$ & 0.17 & 30 & $(35.8,-18.2)$ & $(-, 18)$ \\
11 & $(2.1,-17.1)$ & $(11,14)$ & 0.08 & 31 & $(42.4,-16.1)$ & $(-, 18)$ \\
12 & $(15.2,-15.1)$ & $(9,12)$ & 0.06 & 32 & $(49.7,-14.2)$ & $(-, 18)$ \\
13 & $(0.1,2.2)$ & $(13,15)$ & 0.10 & 33 & $(38.5,5.3)$ & $(-, 18)$ \\
14 & $(10,3.7)$ & $(10,12)$ & 0.16 & 34 & $(65,-16.1)$ & $(-, 15)$ \\
15 & $(5.2,8.7)$ & $(12,14)$ & 0.08 & 35 & $(58,2.1)$ & $(-, 18)$ \\
16 & $(15.6,0.5)$ & $(10,13)$ & 0.11 & 36 & $(42.1,-12.9)$ & $(-, 17)$ \\
17 & $(-4.8,8.2)$ & $(11,14)$ & 0.15 & 37 & $(66.5,7.9)$ & $(-, 18)$ \\
18 & $(-7.2,0.2)$ & $(11,13)$ & 0.06 & 38 & $(43.2,16.6)$ & $(-, 17)$ \\
19 & $(14,5.2)$ & $(10,14)$ & 0.12 & 39 & $(41.6,11.6)$ & $(-, 18)$ \\
20 & $(-4.8,-12)$ & $(12,14)$ & 0.13 & 40 & $(35.7,9)$ & $(-, 17)$ \\
\hline
\end{tabular}

\subsection{Solution of the Model}

\subsubsection{Basic Scenario}

We repeated the experiment 10 times and found that the optimal total delivery time was $85.9 \mathrm{~h}$; the total time outside the time window was $1.1 \mathrm{~h}$. The comprised waiting time of $0.9 \mathrm{~h}$ was caused by the courier arriving before the time window, and delay time of $0.2 \mathrm{~h}$ was caused by the courier arriving after the delivery time window. Figure 2 shows the delivery path that resulted from this analysis. 


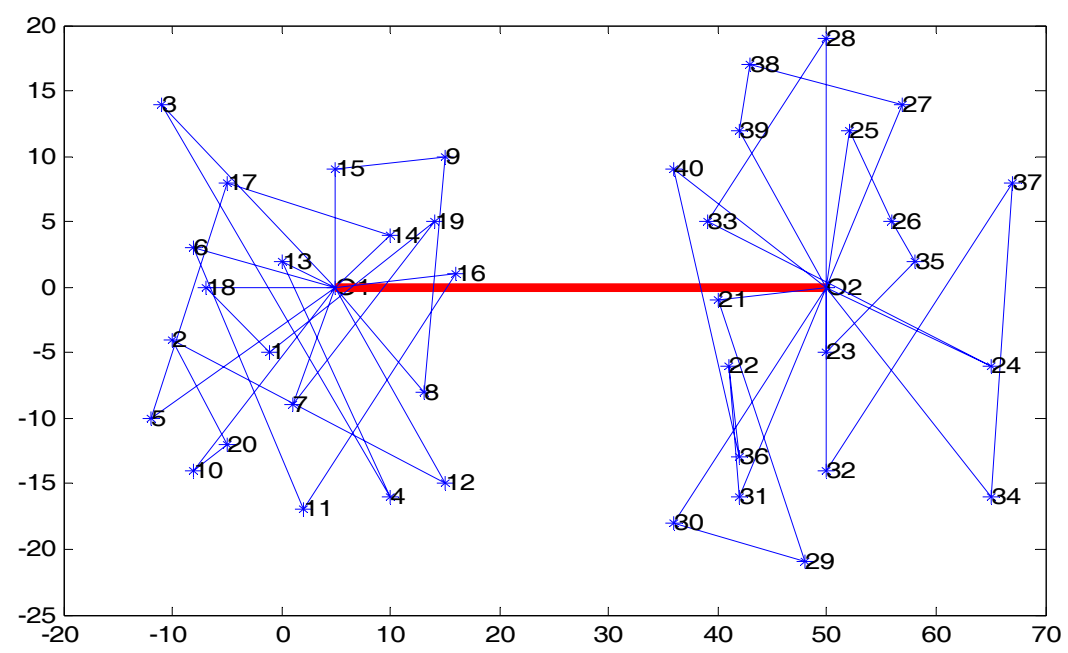

Figure 2. Illustration of the vehicle paths produced by the genetic algorithm.

Table 2 shows the path information and departure time information for each vehicle. Table 3 shows the pickup time, arrival time, and path of each vehicle. Table 3 shows that the shortest delivery time was for delivery 18 , which took $2.71 \mathrm{~h}$, and the longest time was for delivery 12 , which took $7.56 \mathrm{~h}$.

Table 2. Vehicle path information.

\begin{tabular}{ccccccc}
\hline & \multicolumn{2}{c}{ Pickup } & \multicolumn{3}{c}{ Subway } & \multicolumn{3}{c}{ Delivery } \\
\hline $\begin{array}{c}\text { Vehicle } \\
\text { Number }\end{array}$ & $\begin{array}{c}\text { Departure } \\
\text { Time }\end{array}$ & Path & $\begin{array}{c}\text { Departure } \\
\text { Time }\end{array}$ & $\begin{array}{c}\text { Vehicle } \\
\text { Number }\end{array}$ & $\begin{array}{c}\text { Departure } \\
\text { Time }\end{array}$ & Path \\
\hline 1 & $09: 05$ & $0-7-19-1-18-0$ & $12: 00$ & 1 & $13: 29$ & $0-21-29-30-0$ \\
2 & $09: 13$ & $0-6-11-16-0$ & $13: 00$ & 2 & $13: 29$ & $0-40-36-22-31-0$ \\
3 & $08: 33$ & $0-12-2-20-10-0$ & $13: 00$ & 3 & $13: 29$ & $0-34-37-32-0$ \\
4 & $10: 32$ & $0-8-9-15-0$ & $13: 00$ & 4 & $12: 31$ & $0-27-38-39-0$ \\
5 & $08: 43$ & $0-14-17-5-0$ & $13: 00$ & 5 & $14: 30$ & $0-28-33-24-0$ \\
6 & $09: 54$ & $0-3-4-13-0$ & $14: 00$ & 6 & $14: 31$ & $0-25-26-35-23-0$ \\
\hline
\end{tabular}

Table 3. Pickup and arrival time.

\begin{tabular}{cccc}
\hline Delivery Number & Pickup Time & Arrival Time & Total Time \\
\hline$(1)$ & $10: 54$ & $14: 00$ & 3.10 \\
$(2)$ & $11: 00$ & $15: 49$ & 4.83 \\
$(3)$ & $10: 10$ & $16: 13$ & 6.05 \\
$(4)$ & $12: 00$ & $17: 45$ & 5.75 \\
$(5)$ & $11: 57$ & $15: 06$ & 3.14 \\
$(6)$ & $09: 52$ & $15: 30$ & 5.63 \\
$(7)$ & $09: 02$ & $13: 16$ & 4.24 \\
$(8)$ & $11: 05$ & $15: 27$ & 4.36 \\
$(9)$ & $12: 00$ & $15: 04$ & 3.08 \\
$(10)$ & $11: 39$ & $15: 41$ & 4.05 \\
$(11)$ & $11: 00$ & $16: 19$ & 5.33 \\
$(12)$ & $9: 38$ & $17: 11$ & 7.56 \\
$(13)$ & $13: 01$ & $16: 20$ & 3.31 \\
$(14)$ & $10: 13$ & $14: 35$ & 4.37 \\
$(15)$ & $12: 30$ & $15: 41$ & 3.19 \\
$(16)$ & $12: 08$ & $15: 28$ & 3.33 \\
$(17)$ & $11: 00$ & $15: 48$ & 4.80 \\
$(18)$ & $11: 17$ & $13: 59$ & 2.71 \\
$(19)$ & $10: 00$ & $14: 15$ & 4.25 \\
$(20)$ & $11: 28$ & $14: 19$ & 2.86 \\
\hline
\end{tabular}


From the genetic algorithm data, we can create a convergence curve (Figure 3) in which the horizontal coordinate represents the number of iterations, and the vertical axis represents the average value of the population objective function. In our simulations, this value converged and began to stabilize at a mean of around $2.4 \times 10^{6}$ after 250 generations.

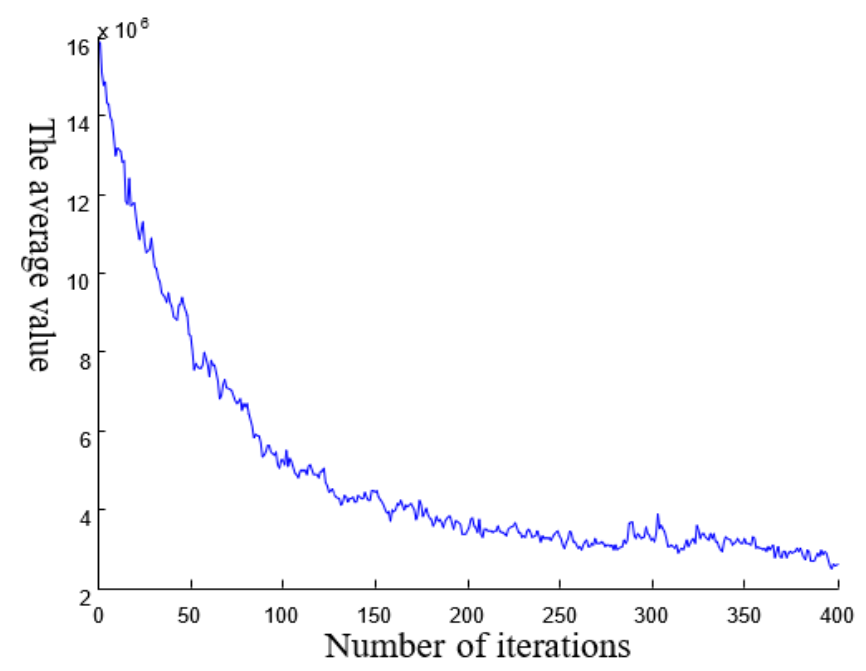

Figure 3. Convergence curve for the genetic algorithm.

\subsubsection{Scenario 1: Changing the Coordinates}

Based on the original scenario, we exchanged the coordinates of sender and recipient in scenario 1. The new sender's coordinates were changed to the former corresponding recipient's coordinates. The new recipient's coordinates were changed to the corresponding former sender's coordinates. Table 4 shows the updated data.

Table 4. Scenario 1: Locations, time windows, and volume of the package.

\begin{tabular}{ccccccc}
\hline \multicolumn{1}{c}{ Package } & Sender & Package & & Recipient & \\
Number & Coordinates & $\begin{array}{c}\text { Time } \\
\text { Window }\end{array}$ & Volume & $\begin{array}{c}\text { Package } \\
\text { Number }\end{array}$ & Coordinates & $\begin{array}{c}\text { Time } \\
\text { Window }\end{array}$ \\
\hline 1 & $(40,-1.4)$ & $(8,11)$ & 0.08 & 21 & $(-1.3,-5.3)$ & $(-, 16)$ \\
2 & $(41,-5.5)$ & $(11,13)$ & 0.13 & 22 & $(-10.4,-3.5)$ & $(-, 17)$ \\
3 & $(50,-4.7)$ & $(9,12)$ & 0.05 & 23 & $(-11.4,14)$ & $(-, 16)$ \\
4 & $(65,-5.8)$ & $(12,14)$ & 0.16 & 24 & $(9.6,-15.7)$ & $(-, 18)$ \\
5 & $(52,11.6)$ & $(10,15)$ & 0.08 & 25 & $(-12.2,-10)$ & $(-, 18)$ \\
6 & $(56.3,5.3)$ & $(9,11)$ & 0.06 & 26 & $(-7.9,2.7)$ & $(-, 17)$ \\
7 & $(56.5,13.7)$ & $(8,10)$ & 0.10 & 27 & $(-5,-11.6)$ & $(-, 14)$ \\
8 & $(50.4,18.9)$ & $(10,14)$ & 0.13 & 28 & $(13,-7.6)$ & $(-, 17)$ \\
9 & $(48.2,-21)$ & $(12,14)$ & 0.15 & 29 & $(15.4,9.9)$ & $(-, 16)$ \\
10 & $(35.8,-18.2)$ & $(12,15)$ & 0.17 & 30 & $(-7.8,-14)$ & $(-, 18)$ \\
11 & $(42.4,-16.1)$ & $(11,14)$ & 0.08 & 31 & $(2.1,-17.1)$ & $(-, 18)$ \\
12 & $(49.7,-14.2)$ & $(9,12)$ & 0.06 & 32 & $(15.2,-15.1)$ & $(-, 18)$ \\
13 & $(38.5,5.3)$ & $(13,15)$ & 0.10 & 33 & $(0.1,2.2)$ & $(-, 18)$ \\
14 & $(65,-16.1)$ & $(10,12)$ & 0.16 & 34 & $(10,3.7)$ & $(-, 15)$ \\
15 & $(58,2.1)$ & $(12,14)$ & 0.08 & 35 & $(5.2,8.7)$ & $(-, 18)$ \\
16 & $(42.1,-12.9)$ & $(10,13)$ & 0.11 & 36 & $(15.6,0.5)$ & $(-, 17)$ \\
17 & $(66.5,7.9)$ & $(11,14)$ & 0.15 & 37 & $(-4.8,8.2)$ & $(-, 18)$ \\
18 & $(43.2,16.6)$ & $(11,13)$ & 0.06 & 38 & $(-7.2,0.2)$ & $(-, 17)$ \\
19 & $(41.6,11.6)$ & $(10,14)$ & 0.12 & 39 & $(14,5.2)$ & $(-, 18)$ \\
20 & $(35.7,9)$ & $(12,14)$ & 0.13 & 40 & $(-4.8,-12)$ & $(-, 17)$ \\
\hline
\end{tabular}

In scenario 1 , the optimal total delivery time was $89.7 \mathrm{~h}$, and the total time exceeding the time window was $0.6 \mathrm{~h}$. This included a waiting time of $0.36 \mathrm{~h}$ caused by the courier arriving before the 
beginning of the time window and a delay of $0.25 \mathrm{~h}$ caused by the courier arriving after the end of the time window. Figure 4 shows the delivery path that resulted from this analysis.

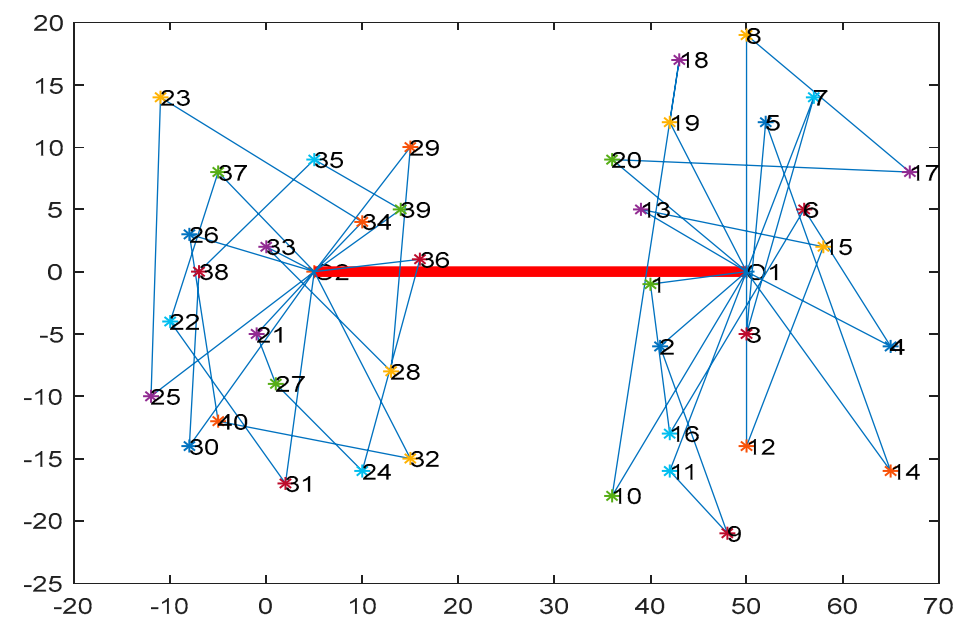

Figure 4. Scenario 1: Illustration of the vehicle paths produced by the genetic algorithm.

Table 5 shows the path information and departure time information for each vehicle. Table 6 shows the pickup time, arrival time, and path of each vehicle. Table 6 further shows that delivery 14 had the shortest delivery time, which took $2.42 \mathrm{~h}$; and delivery 5 took the longest time, which was $6.33 \mathrm{~h}$.

Table 5. Scenario 1: Vehicle path information.

\begin{tabular}{ccccccc}
\hline & \multicolumn{2}{c}{ Pickup } & \multicolumn{3}{c}{ Subway } \\
$\begin{array}{c}\text { Vehicle } \\
\text { Number }\end{array}$ & $\begin{array}{c}\text { Departure } \\
\text { Time }\end{array}$ & Path & $\begin{array}{c}\text { Departure } \\
\text { Time }\end{array}$ & $\begin{array}{c}\text { Vehicle } \\
\text { Number }\end{array}$ & $\begin{array}{c}\text { Departure } \\
\text { Time }\end{array}$ & Path \\
\hline 1 & $09: 02$ & $0-8-17-20-0$ & $14: 00$ & 1 & $14: 30$ & $0-29-28-33-0$ \\
2 & $07: 12$ & $0-7-3-5-14-0$ & $13: 00$ & 2 & $14: 30$ & $0-39-35-38-30-0$ \\
3 & $10: 01$ & $0-19-18-10-0$ & $14: 00$ & 3 & $13: 30$ & $0-34-23-25-0$ \\
4 & $10: 43$ & $0-11-9-2-0$ & $14: 00$ & 4 & $14: 30$ & $0-37-22-31-0$ \\
5 & $10: 24$ & $0-12-15-13-0$ & $14: 00$ & 5 & $14: 30$ & $0-26-40-32-0$ \\
6 & $08: 53$ & $0-1-16-6-4-0$ & $13: 00$ & 6 & $13: 30$ & $0-21-27-24-36-0$ \\
\hline
\end{tabular}

Table 6. Scenario 1: Pickup and arrival time.

\begin{tabular}{cccc}
\hline Delivery Number & Pickup Time & Arrival Time & Total Time \\
\hline$(1)$ & $09: 24$ & $13: 53$ & 4.50 \\
$(2)$ & $12: 49$ & $15: 47$ & 2.96 \\
$(3)$ & $9: 00$ & $14: 59$ & 5.98 \\
$(4)$ & $11: 51$ & $14: 41$ & 2.83 \\
$(5)$ & $09: 51$ & $16: 11$ & 6.33 \\
$(6)$ & $11: 08$ & $15: 10$ & 4.03 \\
$(7)$ & $07: 59$ & $14: 06$ & 6.13 \\
$(8)$ & $09: 59$ & $16: 06$ & 6.13 \\
$(9)$ & $12: 00$ & $15: 12$ & 3.21 \\
$(10)$ & $12: 47$ & $16: 57$ & 4.17 \\
$(11)$ & $11: 36$ & $16: 40$ & 5.07 \\
$(12)$ & $11: 06$ & $16: 56$ & 5.84 \\
$(13)$ & $12: 57$ & $16: 56$ & 3.97 \\
$(14)$ & $11: 24$ & $13: 49$ & 2.42 \\
$(15)$ & $12: 00$ & $15: 30$ & 3.51 \\
$(16)$ & $10: 00$ & $15: 35$ & 5.59 \\
$(17)$ & $11: 00$ & $15: 08$ & 4.14 \\
$(18)$ & $11: 00$ & $16: 15$ & 5.26 \\
$(19)$ & $10: 44$ & $15: 00$ & 4.27 \\
$(20)$ & $12: 33$ & $15: 55$ & 3.38 \\
\hline
\end{tabular}




\subsubsection{Scenario 2: Changing the Time Windows}

Based on the original scenario, we changed the time windows of sender and recipient in scenario 2. We exchanged the time windows between the first and the last sender package number: 1 and 20, 2 and 19, and so on. As for the senders, we exchanged the time windows between the first and the last recipient package number: 21 and 40, 22 and 39, and so on. Table 7 shows the updated data.

Table 7. Scenario 2: Locations, time windows, and volume of the package.

\begin{tabular}{ccccccc}
\hline & Sender & & Package & & Recipient & Time \\
\hline $\begin{array}{c}\text { Package } \\
\text { Number }\end{array}$ & Coordinates & $\begin{array}{c}\text { Time } \\
\text { Window }\end{array}$ & Volume & $\begin{array}{c}\text { Package } \\
\text { Number }\end{array}$ & Coordinates & $\begin{array}{c}\text { Tindow } \\
\text { Window }\end{array}$ \\
\hline 1 & $(-1.3,-5.3)$ & $(12,14)$ & 0.08 & 21 & $(40,-1.4)$ & $(-, 17)$ \\
2 & $(-10.4,-3.5)$ & $(10,14)$ & 0.13 & 22 & $(41,-5.5)$ & $(-, 18)$ \\
3 & $(-11.4,14)$ & $(11,13)$ & 0.05 & 23 & $(50,-4.7)$ & $(-, 17)$ \\
4 & $(9.6,-15.7)$ & $(11,14)$ & 0.16 & 24 & $(65,-5.8)$ & $(-, 18)$ \\
5 & $(-12.2,-10)$ & $(10,13)$ & 0.08 & 25 & $(52,11.6)$ & $(-, 17)$ \\
6 & $(-7.9,2.7)$ & $(12,14)$ & 0.06 & 26 & $(56.3,5.3)$ & $(-, 18)$ \\
7 & $(-5,-11.6)$ & $(10,12)$ & 0.10 & 27 & $(56.5,13.7)$ & $(-, 15)$ \\
8 & $(13,-7.6)$ & $(13,15)$ & 0.13 & 28 & $(50.4,18.9)$ & $(-, 18)$ \\
9 & $(15.4,9.9)$ & $(9,12)$ & 0.15 & 29 & $(48.2,-21)$ & $(-, 18)$ \\
10 & $(-7.8,-14)$ & $(11,14)$ & 0.17 & 30 & $(35.8,-18.2)$ & $(-, 18)$ \\
11 & $(2.1,-17.1)$ & $(12,15)$ & 0.08 & 31 & $(42.4,-16.1)$ & $(-, 18)$ \\
12 & $(15.2,-15.1)$ & $(12,14)$ & 0.06 & 32 & $(49.7,-14.2)$ & $(-, 16)$ \\
13 & $(0.1,2.2)$ & $(10,14)$ & 0.10 & 33 & $(38.5,5.3)$ & $(-, 17)$ \\
14 & $(10,3.7)$ & $(8,10)$ & 0.16 & 34 & $(65,-16.1)$ & $(-, 14)$ \\
15 & $(5.2,8.7)$ & $(9,11)$ & 0.08 & 35 & $(58,2.1)$ & $(-, 17)$ \\
16 & $(15.6,0.5)$ & $(10,15)$ & 0.11 & 36 & $(42.1,-12.9)$ & $(-, 18)$ \\
17 & $(-4.8,8.2)$ & $(12,14)$ & 0.15 & 37 & $(66.5,7.9)$ & $(-, 18)$ \\
18 & $(-7.2,0.2)$ & $(9,12)$ & 0.06 & 38 & $(43.2,16.6)$ & $(-, 16)$ \\
19 & $(14,5.2)$ & $(11,13)$ & 0.12 & 39 & $(41.6,11.6)$ & $(-, 17)$ \\
20 & $(-4.8,-12)$ & $(8,11)$ & 0.13 & 40 & $(35.7,9)$ & $(-, 16)$ \\
\hline
\end{tabular}

In scenario 2, the optimal total delivery time was $91.9 \mathrm{~h}$ and the total time exceeding the time window was $1.55 \mathrm{~h}$. This included a waiting time of $0.13 \mathrm{~h}$ caused by the courier arriving before the beginning of the time window and a delay of $1.42 \mathrm{~h}$ caused by the courier arriving after the end of the time window. Figure 5 shows the delivery path that resulted from this analysis.

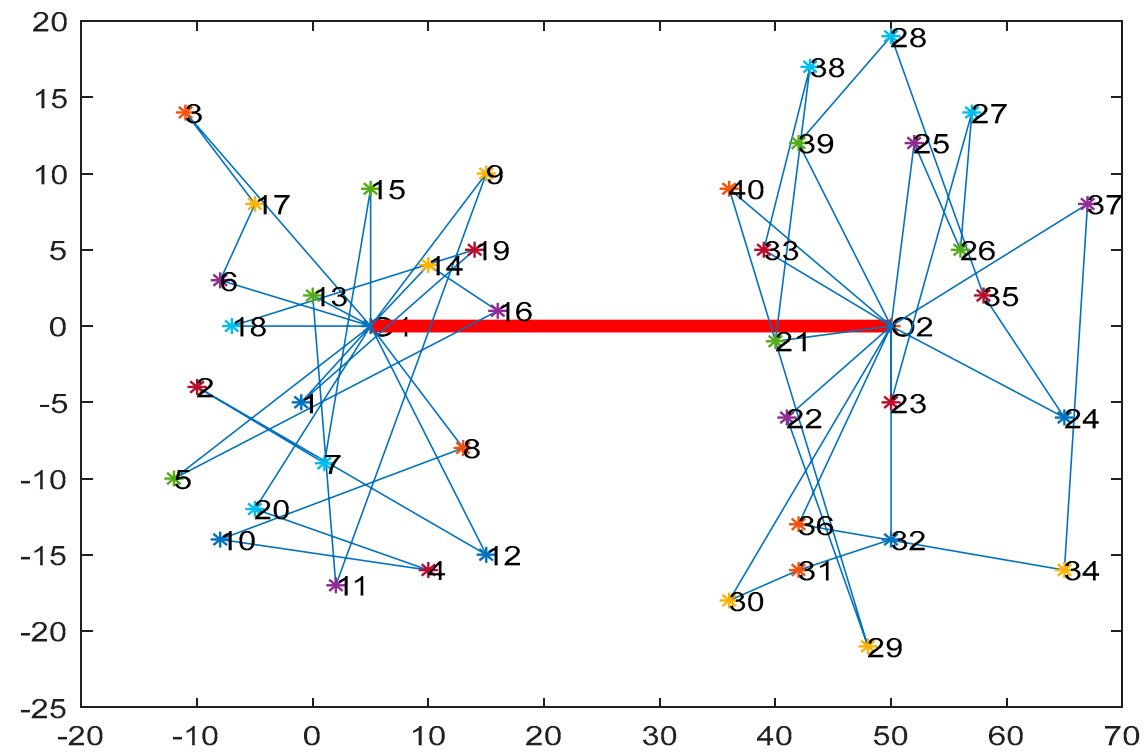

Figure 5. Scenario 2: Illustration of the vehicle paths produced by the genetic algorithm. 
Table 8 shows the path information and departure time information for each vehicle. Table 9 shows the pickup time, arrival time, and path of each vehicle. Table 9 further shows that delivery 6 had the shortest delivery time, which was $2.22 \mathrm{~h}$; and delivery 15 took the longest time, which was $7.61 \mathrm{~h}$.

Table 8. Scenario 2: Vehicle path information.

\begin{tabular}{ccccccc}
\hline & \multicolumn{2}{c}{ Pickup } & \multicolumn{3}{c}{ Dubway } \\
\hline $\begin{array}{c}\text { Vehicle } \\
\text { Number }\end{array}$ & $\begin{array}{c}\text { Departure } \\
\text { Time }\end{array}$ & Path & $\begin{array}{c}\text { Departure } \\
\text { Time }\end{array}$ & $\begin{array}{c}\text { Vehicle } \\
\text { Number }\end{array}$ & $\begin{array}{c}\text { Departure } \\
\text { Time }\end{array}$ & Path \\
\hline 1 & $09: 20$ & $0-14-16-5-0$ & $13: 00$ & 1 & $14: 30$ & $0-40-29-22-0$ \\
2 & $09: 27$ & $0-20-4-10-8-0$ & $14: 00$ & 2 & $14: 30$ & $0-39-28-35-24-0$ \\
3 & $09: 48$ & $0-9-11-13-0$ & $14: 00$ & 3 & $13: 30$ & $0-36-34-37-0$ \\
4 & $09: 19$ & $0-18-19-1-0$ & $13: 00$ & 4 & $14: 30$ & $0-21-38-33-0$ \\
5 & $10: 31$ & $0-3-17-6-0$ & $13: 00$ & 5 & $14: 30$ & $0-32-31-30-0$ \\
6 & $08: 38$ & $0-15-7-2-12-0$ & $13: 00$ & 6 & $13: 30$ & $0-25-26-27-23-0$ \\
\hline
\end{tabular}

Table 9. Scenario 2: Pickup and arrival time.

\begin{tabular}{cccc}
\hline Delivery Number & Pickup Time & Arrival Time & Total Time \\
\hline$(1)$ & $11: 54$ & $15: 00$ & 3.10 \\
$(2)$ & $10: 36$ & $17: 46$ & 7.17 \\
$(3)$ & $11: 34$ & $15: 58$ & 4.40 \\
$(4)$ & $11: 00$ & $17: 13$ & 6.22 \\
$(5)$ & $11: 30$ & $14: 06$ & 2.60 \\
$(6)$ & $12: 17$ & $14: 30$ & 2.22 \\
$(7)$ & $10: 00$ & $14: 57$ & 4.96 \\
$(8)$ & $12: 59$ & $15: 45$ & 2.76 \\
$(9)$ & $10: 30$ & $16: 56$ & 6.45 \\
$(10)$ & $11: 54$ & $15: 55$ & 4.02 \\
$(11)$ & $12: 00$ & $15: 36$ & 3.61 \\
$(12)$ & $11: 58$ & $15: 12$ & 3.23 \\
$(13)$ & $12: 57$ & $16: 32$ & 3.59 \\
$(14)$ & $09: 39$ & $15: 25$ & 5.76 \\
$(15)$ & $09: 04$ & $16: 41$ & 7.61 \\
$(16)$ & $10: 00$ & $14: 15$ & 4.26 \\
$(17)$ & $12: 00$ & $16: 37$ & 4.63 \\
$(18)$ & $09: 55$ & $15: 54$ & 5.99 \\
$(19)$ & $11: 00$ & $15: 13$ & 4.22 \\
$(20)$ & $10: 13$ & $15: 19$ & 5.11 \\
\hline
\end{tabular}

\subsubsection{Scenario 3: Changing the Volume}

Based on the original scenario, we changed the volume of each package in scenario 3 . The new package volume equals the former package volume times 0.8 . Table 10 shows the updated data.

In scenario 3, the optimal total delivery time was $90.52 \mathrm{~h}$ and the total time exceeding the time window was $1.86 \mathrm{~h}$. This included a waiting time of $0.41 \mathrm{~h}$ caused by the courier arriving before the beginning of the time window and a delay of $1.45 \mathrm{~h}$ caused by the courier arriving after the end of the time window. Figure 6 shows the delivery path that resulted from this analysis.

Table 11 shows the path information and departure time information for each vehicle. Table 12 shows the pickup time, arrival time, and path of each vehicle. Table 12 further shows that delivery 9 had the shortest delivery time, which was $2.55 \mathrm{~h}$; and delivery 17 took the longest time, which was $6.31 \mathrm{~h}$. 
Table 10. Scenario 3: Locations, time windows, and volume of the package.

\begin{tabular}{|c|c|c|c|c|c|c|}
\hline \multicolumn{3}{|c|}{ Sender } & \multirow{2}{*}{$\begin{array}{l}\text { Package } \\
\text { Volume }\end{array}$} & \multicolumn{3}{|c|}{ Recipient } \\
\hline $\begin{array}{l}\text { Package } \\
\text { Number }\end{array}$ & Coordinates & $\begin{array}{c}\text { Time } \\
\text { Window }\end{array}$ & & $\begin{array}{l}\text { Package } \\
\text { Number }\end{array}$ & Coordinates & $\begin{array}{c}\text { Time } \\
\text { Window }\end{array}$ \\
\hline 1 & $(-1.3,-5.3)$ & $(8,11)$ & 0.064 & 21 & $(40,-1.4)$ & $(-, 16)$ \\
\hline 2 & $(-10.4,-3.5)$ & $(11,13)$ & 0.104 & 22 & $(41,-5.5)$ & $(-, 17)$ \\
\hline 3 & $(-11.4,14)$ & $(9,12)$ & 0.04 & 23 & $(50,-4.7)$ & $(-, 16)$ \\
\hline 4 & $(9.6,-15.7)$ & $(12,14)$ & 0.128 & 24 & $(65,-5.8)$ & $(-, 18)$ \\
\hline 5 & $(-12.2,-10)$ & $(10,15)$ & 0.064 & 25 & $(52,11.6)$ & $(-, 18)$ \\
\hline 6 & $(-7.9,2.7)$ & $(9,11)$ & 0.048 & 26 & $(56.3,5.3)$ & $(-, 17)$ \\
\hline 7 & $(-5,-11.6)$ & $(8,10)$ & 0.08 & 27 & $(56.5,13.7)$ & $(-, 14)$ \\
\hline 8 & $(13,-7.6)$ & $(10,14)$ & 0.104 & 28 & $(50.4,18.9)$ & $(-, 17)$ \\
\hline 9 & $(15.4,9.9)$ & $(12,14)$ & 0.12 & 29 & $(48.2,-21)$ & $(-, 16)$ \\
\hline 10 & $(-7.8,-14)$ & $(12,15)$ & 0.136 & 30 & $(35.8,-18.2)$ & $(-, 18)$ \\
\hline 11 & $(2.1,-17.1)$ & $(11,14)$ & 0.064 & 31 & $(42.4,-16.1)$ & $(-, 18)$ \\
\hline 12 & $(15.2,-15.1)$ & $(9,12)$ & 0.048 & 32 & $(49.7,-14.2)$ & $(-, 18)$ \\
\hline 13 & $(0.1,2.2)$ & $(13,15)$ & 0.08 & 33 & $(38.5,5.3)$ & $(-, 18)$ \\
\hline 14 & $(10,3.7)$ & $(10,12)$ & 0.16 & 34 & $(65,-16.1)$ & $(-, 15)$ \\
\hline 15 & $(5.2,8.7)$ & $(12,14)$ & 0.08 & 35 & $(58,2.1)$ & $(-, 18)$ \\
\hline 16 & $(15.6,0.5)$ & $(10,13)$ & 0.11 & 36 & $(42.1,-12.9)$ & $(-, 17)$ \\
\hline 17 & $(-4.8,8.2)$ & $(11,14)$ & 0.15 & 37 & $(66.5,7.9)$ & $(-, 18)$ \\
\hline 18 & $(-7.2,0.2)$ & $(11,13)$ & 0.06 & 38 & $(43.2,16.6)$ & $(-, 17)$ \\
\hline 19 & $(14,5.2)$ & $(10,14)$ & 0.12 & 39 & $(41.6,11.6)$ & $(-, 18)$ \\
\hline 20 & $(-4.8,-12)$ & $(12,14)$ & 0.13 & 40 & $(35.7,9)$ & $(-, 17)$ \\
\hline
\end{tabular}

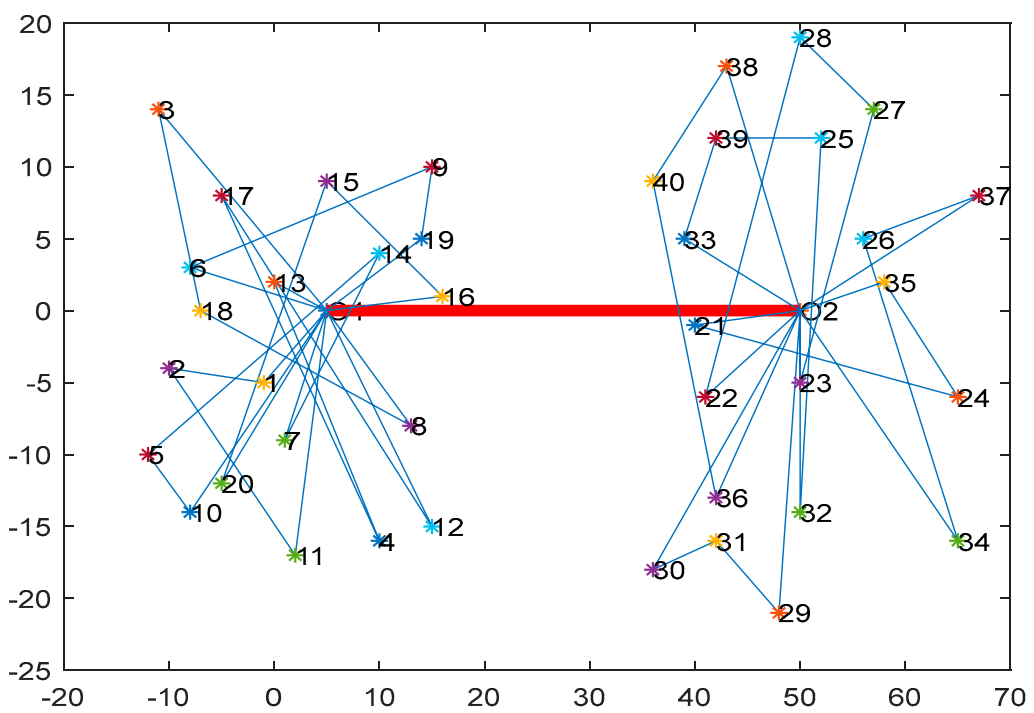

Figure 6. Scenario 3: Illustration of the vehicle paths produced by the genetic algorithm.

Table 11. Scenario 3: Vehicle path information.

\begin{tabular}{ccccccc}
\hline & \multicolumn{2}{c}{ Pickup } & \multicolumn{3}{c}{ Subway } & \multicolumn{3}{c}{ Delivery } \\
\hline $\begin{array}{c}\text { Vehicle } \\
\text { Number }\end{array}$ & $\begin{array}{c}\text { Departure } \\
\text { Time }\end{array}$ & Path & $\begin{array}{c}\text { Departure } \\
\text { Time }\end{array}$ & $\begin{array}{c}\text { Vehicle } \\
\text { Number }\end{array}$ & $\begin{array}{c}\text { Departure } \\
\text { Time }\end{array}$ & Path \\
\hline 1 & $10: 09$ & $0-1-2-11-0$ & $13: 00$ & 1 & $13: 30$ & $0-29-31-30-0$ \\
2 & $08: 34$ & $0-12-17-4-13-0$ & $14: 00$ & 2 & $14: 30$ & $0-32-25-39-33-0$ \\
3 & $10: 46$ & $0-16-15-20-0$ & $14: 00$ & 3 & $14: 30$ & $0-38-40-36-0$ \\
4 & $10: 08$ & $0-6-9-19-0$ & $13: 00$ & 4 & $14: 30$ & $0-34-26-37-0$ \\
5 & $09: 13$ & $0-3-18-8-0$ & $13: 00$ & 5 & $14: 30$ & $0-21-24-35-0$ \\
6 & $08: 43$ & $0-7-14-5-10-0$ & $13: 00$ & 6 & $13: 30$ & $0-23-27-28-22-0$ \\
\hline
\end{tabular}


Table 12. Scenario 3: Pickup and arrival time.

\begin{tabular}{cccc}
\hline Delivery Number & Pickup Time & Arrival Time & Total Time \\
\hline$(1)$ & $10: 32$ & $15: 00$ & 4.46 \\
$(2)$ & $11: 00$ & $16: 31$ & 5.52 \\
$(3)$ & $10: 16$ & $13: 45$ & 3.48 \\
$(4)$ & $12: 24$ & $16: 16$ & 3.86 \\
$(5)$ & $11: 18$ & $16: 30$ & 5.20 \\
$(6)$ & $10: 47$ & $16: 44$ & 5.94 \\
$(7)$ & $09: 12$ & $14: 45$ & 5.55 \\
$(8)$ & $12: 04$ & $15: 11$ & 3.12 \\
$(9)$ & $12: 00$ & $14: 33$ & 2.55 \\
$(10)$ & $11: 35$ & $15: 15$ & 3.67 \\
$(11)$ & $11: 53$ & $14: 56$ & 3.06 \\
$(12)$ & $09: 28$ & $15: 12$ & 5.72 \\
$(13)$ & $13: 26$ & $17: 23$ & 3.94 \\
$(14)$ & $10: 00$ & $15: 35$ & 5.60 \\
$(15)$ & $12: 00$ & $16: 48$ & 4.81 \\
$(16)$ & $11: 19$ & $17: 05$ & 5.77 \\
$(17)$ & $11: 00$ & $17: 18$ & 6.31 \\
$(18)$ & $11: 00$ & $15: 25$ & 4.42 \\
$(19)$ & $12: 15$ & $17: 00$ & 4.75 \\
$(20)$ & $13: 09$ & $15: 57$ & 2.79 \\
\hline
\end{tabular}

\subsubsection{Scenario 4: Changing the Volume}

Based on the original scenario, we changed the volume of each package in scenario 4 . The new package volume equals the former package volume times 1.2. Table 13 shows the updated data.

Table 13. Scenario 4: Locations, time windows, and volume of the package.

\begin{tabular}{ccccccc}
\hline & Sender & & Package & & Recipient & Time \\
\hline $\begin{array}{c}\text { Package } \\
\text { Number }\end{array}$ & Coordinates & $\begin{array}{c}\text { Time } \\
\text { Window }\end{array}$ & Volume & $\begin{array}{c}\text { Package } \\
\text { Number }\end{array}$ & Coordinates & $\begin{array}{c}\text { Tindow } \\
\text { Window }\end{array}$ \\
\hline 1 & $(-1.3,-5.3)$ & $(8,11)$ & 0.096 & 21 & $(40,-1.4)$ & $(-, 16)$ \\
2 & $(-10.4,-3.5)$ & $(11,13)$ & 0.156 & 22 & $(41,-5.5)$ & $(-, 17)$ \\
3 & $(-11.4,14)$ & $(9,12)$ & 0.06 & 23 & $(50,-4.7)$ & $(-, 16)$ \\
4 & $(9.6,-15.7)$ & $(12,14)$ & 0.192 & 24 & $(65,-5.8)$ & $(-, 18)$ \\
5 & $(-12.2,-10)$ & $(10,15)$ & 0.096 & 25 & $(52,11.6)$ & $(-, 18)$ \\
6 & $(-7.9,2.7)$ & $(9,11)$ & 0.072 & 26 & $(56.3,5.3)$ & $(-, 17)$ \\
7 & $(-5,-11.6)$ & $(8,10)$ & 0.12 & 27 & $(56.5,13.7)$ & $(-, 14)$ \\
8 & $(13,-7.6)$ & $(10,14)$ & 0.156 & 28 & $(50.4,18.9)$ & $(-, 17)$ \\
9 & $(15.4,9.9)$ & $(12,14)$ & 0.18 & 29 & $(48.2,-21)$ & $(-, 16)$ \\
10 & $(-7.8,-14)$ & $(12,15)$ & 0.204 & 30 & $(35.8,-18.2)$ & $(-, 18)$ \\
11 & $(2.1,-17.1)$ & $(11,14)$ & 0.096 & 31 & $(42.4,-16.1)$ & $(-, 18)$ \\
12 & $(15.2,-15.1)$ & $(9,12)$ & 0.072 & 32 & $(49.7,-14.2)$ & $(-, 18)$ \\
13 & $(0.1,2.2)$ & $(13,15)$ & 0.12 & 33 & $(38.5,5.3)$ & $(-, 18)$ \\
14 & $(10,3.7)$ & $(10,12)$ & 0.192 & 34 & $(65,-16.1)$ & $(-, 15)$ \\
15 & $(5.2,8.7)$ & $(12,14)$ & 0.096 & 35 & $(58,2.1)$ & $(-, 18)$ \\
16 & $(15.6,0.5)$ & $(10,13)$ & 0.132 & 36 & $(42.1,-12.9)$ & $(-, 17)$ \\
17 & $(-4.8,8.2)$ & $(11,14)$ & 0.18 & 37 & $(66.5,7.9)$ & $(-, 18)$ \\
18 & $(-7.2,0.2)$ & $(11,13)$ & 0.072 & 38 & $(43.2,16.6)$ & $(-, 17)$ \\
19 & $(14,5.2)$ & $(10,14)$ & 0.144 & 39 & $(41.6,11.6)$ & $(-, 18)$ \\
20 & $(-4.8,-12)$ & $(12,14)$ & 0.156 & 40 & $(35.7,9)$ & $(-, 17)$ \\
\hline
\end{tabular}

In scenario 4 , the optimal total delivery time was $86.38 \mathrm{~h}$ and the total time exceeding the time window was $0.49 \mathrm{~h}$. This included a waiting time of $0.37 \mathrm{~h}$ caused by the courier arriving before the beginning of the time window and a delay of $1.12 \mathrm{~h}$ caused by the courier arriving after the end of the time window. Figure 7 shows the delivery path that resulted from this analysis. 


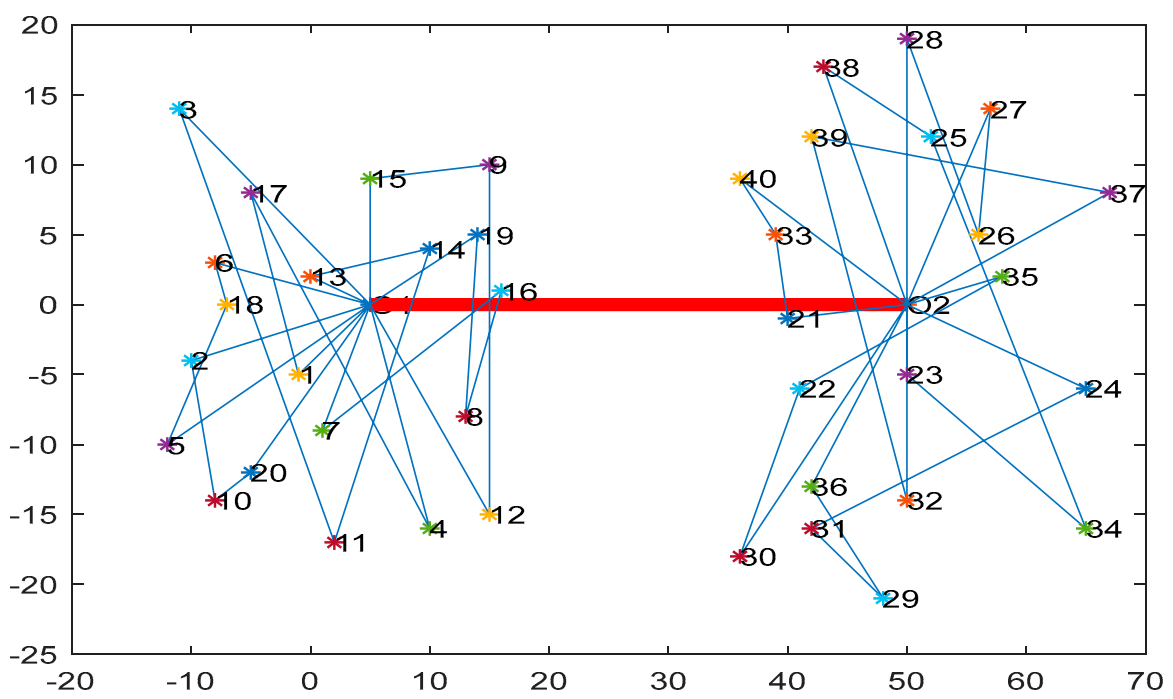

Figure 7. Scenario 4: Illustration of the vehicle paths produced by the genetic algorithm.

Table 14 shows the path information and departure time information for each vehicle. Table 15 shows the pickup time, arrival time, and path of each vehicle. Table 15 further shows that delivery 15 had the shortest delivery time, which was $1.41 \mathrm{~h}$; and the delivery 17 took the longest time, which was $6.83 \mathrm{~h}$.

Table 14. Scenario 4: Vehicle path information.

\begin{tabular}{ccccccc}
\hline & Pickup & \multicolumn{3}{c}{ Subway } & \multicolumn{3}{c}{ Delivery } \\
\hline $\begin{array}{c}\text { Vehicle } \\
\text { Number }\end{array}$ & $\begin{array}{c}\text { Departure } \\
\text { Time }\end{array}$ & Path & $\begin{array}{c}\text { Departure } \\
\text { Time }\end{array}$ & $\begin{array}{c}\text { Vehicle } \\
\text { Number }\end{array}$ & $\begin{array}{c}\text { Departure } \\
\text { Time }\end{array}$ & Path \\
\hline 1 & $09: 51$ & $0-12-9-15-0$ & $13: 00$ & 1 & $13: 30$ & $0-27-26-28-0$ \\
2 & $08: 15$ & $0-3-11-14-13-0$ & $13: 00$ & 2 & $14: 30$ & $0-36-29-31-24-0$ \\
3 & $09: 56$ & $0-1-17-4-0$ & $14: 00$ & 3 & $14: 30$ & $0-32-39-37-0$ \\
4 & $10: 43$ & $0-2-10-20-0$ & $13: 00$ & 4 & $13: 30$ & $0-35-22-30-0$ \\
5 & $10: 10$ & $0-6-18-5-0$ & $13: 00$ & 5 & $14: 30$ & $0-21-33-40-0$ \\
6 & $08: 36$ & $0-7-16-8-19-0$ & $12: 00$ & 6 & $13: 30$ & $0-23-34-25-38-0$ \\
\hline
\end{tabular}

Table 15. Scenario 4: Pickup and arrival time.

\begin{tabular}{cccc}
\hline Delivery Number & Pickup Time & Arrival Time & Total Time \\
\hline$(1)$ & $10: 19$ & $15: 00$ & 4.68 \\
$(2)$ & $11: 29$ & $14: 51$ & 3.36 \\
$(3)$ & $09: 19$ & $13: 45$ & 4.43 \\
$(4)$ & $12: 24$ & $17: 24$ & 4.99 \\
$(5)$ & $11: 33$ & $16: 13$ & 4.66 \\
$(6)$ & $10: 50$ & $14: 44$ & 3.89 \\
$(7)$ & $09: 05$ & $14: 17$ & 5.18 \\
$(8)$ & $10: 28$ & $15: 29$ & 5.02 \\
$(9)$ & $12: 00$ & $15: 45$ & 3.76 \\
$(10)$ & $12: 00$ & $15: 30$ & 3.50 \\
$(11)$ & $11: 00$ & $16: 09$ & 5.15 \\
$(12)$ & $10: 45$ & $15: 12$ & 4.45 \\
$(13)$ & $12: 38$ & $15: 18$ & 2.67 \\
$(14)$ & $12: 07$ & $14: 40$ & 2.56 \\
$(15)$ & $12: 30$ & $13: 54$ & 1.41 \\
$(16)$ & $10: 00$ & $15: 15$ & 5.26 \\
$(17)$ & $11: 00$ & $17: 49$ & 6.83 \\
$(18)$ & $11: 00$ & $16: 44$ & 5.74 \\
$(19)$ & $11: 07$ & $16: 33$ & 5.43 \\
$(20)$ & $12: 10$ & $15: 33$ & 3.38 \\
\hline
\end{tabular}




\subsection{Discussion of the Results}

The above, according to the actual problem encountered in the delivery of courier companies is based on the basic scenario, and the corresponding solutions of the four different scenarios of the model are carried out. However, in the actual express delivery, there were many factors that were found to affect the effectiveness of the express delivery service. Since the influence of different influencing factors on the five transport scenarios is basically similar, in this section, we further study the influence of changes in the number of vehicles, delivery frequency along the subway line, and client time windows on the total delivery time, satisfaction of the client time window satisfaction, and courier company cost based on the basic scenario. The corresponding strategies and suggestions are given according to the research results.

In the empirical analysis, we assumed that the client delivery time window was known, that there were six vehicles each at the collection and distribution hubs, and that each vehicle had a load capacity of $0.5 \mathrm{~m}^{3}$. In the empirical analysis, our use of a soft time window meant that the optimal solution was to meet the time window requirements as soon as possible; thus, the shortest path does not strictly meet the time window requirements. In this section, we studied the influence of changing the number of vehicles, the delivery frequency along the subway line, and the time window on the total delivery time, the satisfaction of time window, and the courier companies' cost. We assumed that purchasing each delivery vehicle cost about 1800 yuan, that each courier earned about 150 yuan per day, and the frequency person in charge of delivery frequency transportation along the subway line earns about 50 yuan each frequency.

\section{(1) Influence of the number of vehicles}

We assumed constant client demand and delivery frequency along the subway line. We found that the overall delivery time decreased with increasing number of vehicles, and that the total time outside the time window also decreased (Figure 8). However, the increased number of workers caused the company costs to increase (Figure 9).

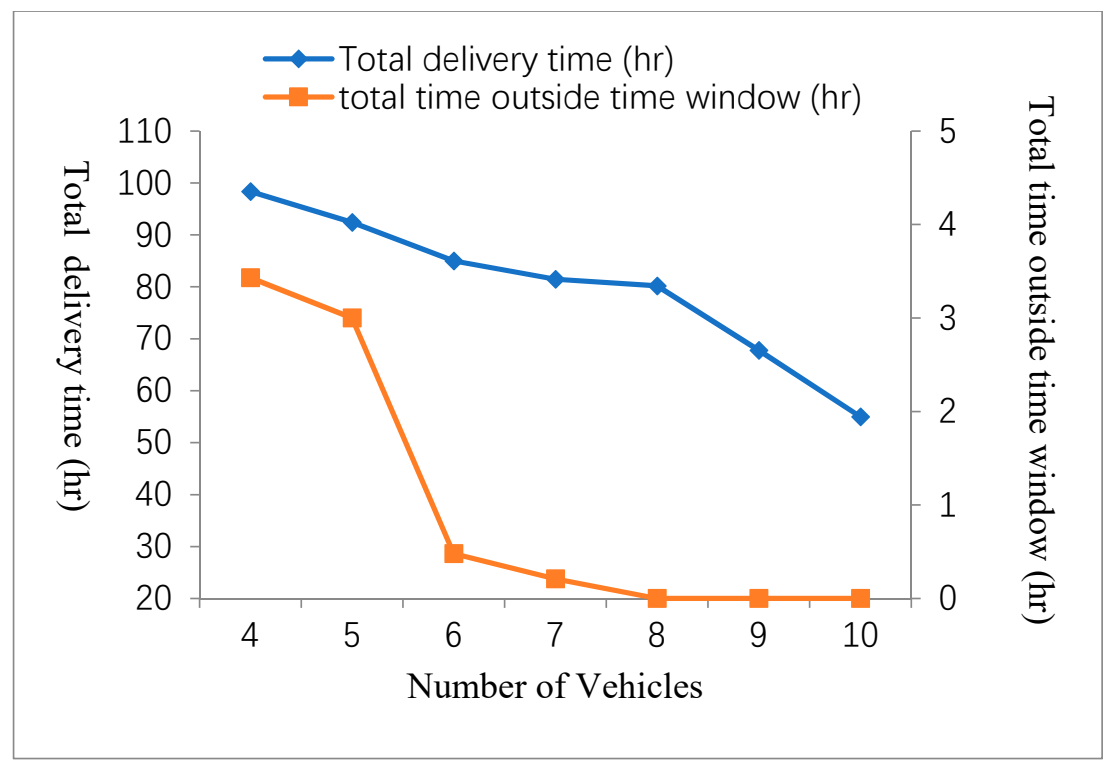

Figure 8. Changes in total delivery time and total time outside the time window as a function of the number of vehicles.

By simultaneously examining the effects of these variables, we found that under the conditions of 20 senders, 20 receivers, one collection hub, one distribution hub, and delivery frequency of once per hour, when the number of vehicles is 6 , the overall delivery time and the total time outside the time window decrease the fastest, that is, the overall delivery time and economy are optimized. If the 
courier must strictly comply with hard time window requirements, in which the total time outside the time window is 0 , then the optimal solution is to use eight vehicles. The quantitative case study creates a model of 20 senders, 20 receivers, one collection hub, one distribution hub, and a delivery frequency of one delivery per hour. If a courier company wants to reduce the total delivery time and the total time outside of the time window, it can use six vehicles to finish all intra-city express deliveries. For a lower total cost, the courier company achieves higher customer satisfaction.

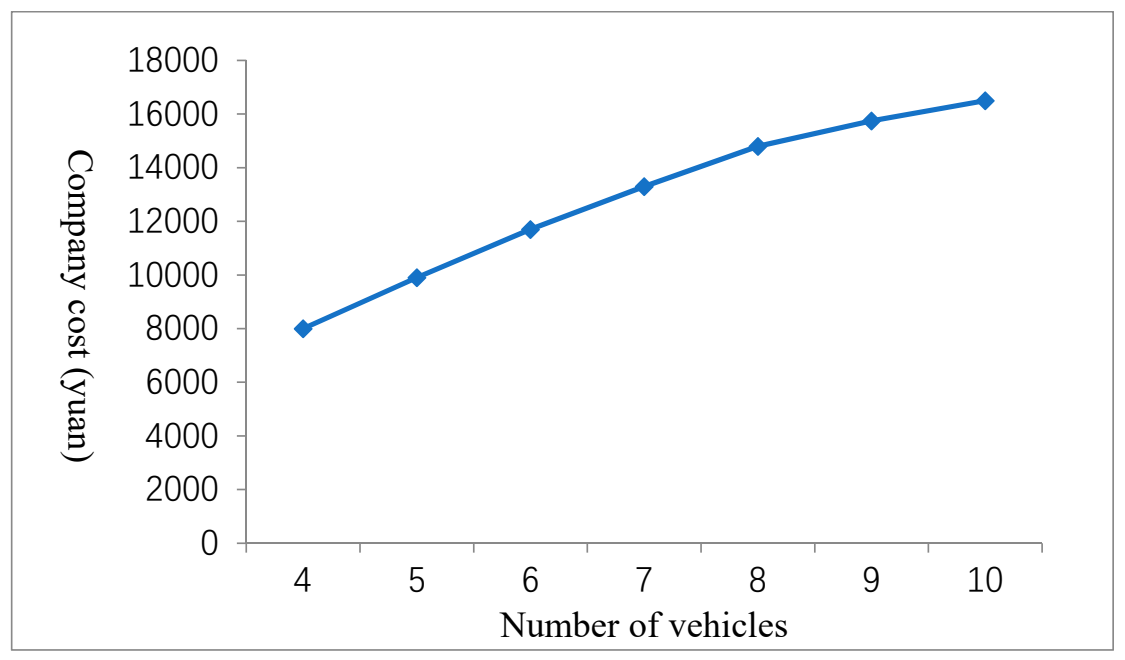

Figure 9. Relationship between the company cost and the number of vehicles.

(2) Influence of changes to delivery frequency along the subway line

We again assumed constant client demand and number of vehicles, then changed the delivery frequency along the subway line. As the delivery interval time decreased, that is, the delivery frequency along the subway line increased, the overall delivery time and the total time outside the time window both decreased (Figure 10). At the same time, the increased delivery frequency along the subway line increased the number for the frequency of people, which caused increased labor costs (Figure 11).

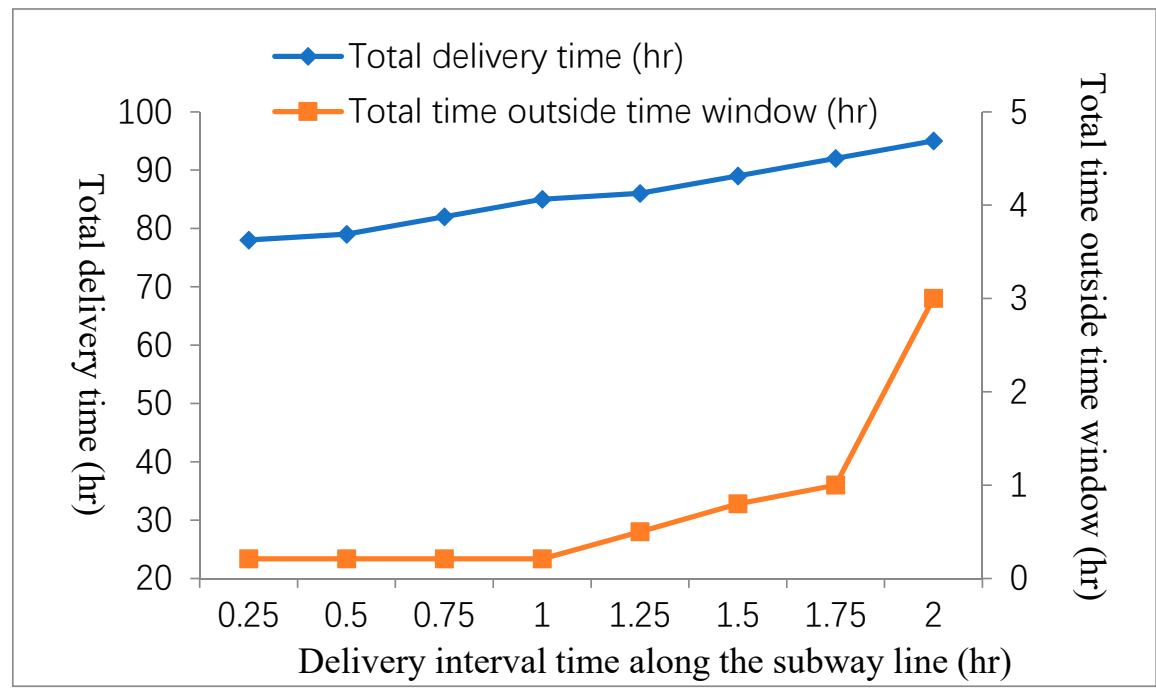

Figure 10. Effect of the delivery interval time along the subway line on the total delivery time and total time outside time window.

By simultaneously examining the effects of these variables, we found that under the conditions of 20 senders, 20 receivers, one collection hub, one distribution hub, and six vehicles, when the delivery interval time along the subway line was one hour, the overall delivery time and labor cost reach the 
optimal balance. The quantitative case study creates a model of 20 senders, 20 receivers, one collection hub, one distribution hub, and six vehicles. If a courier company wants to balance the overall delivery time and cost, it can use the delivery interval time of one hour in line with the subway line's train frequency. At lower total cost, the courier company achieves higher customer satisfaction and shorter delivery time.

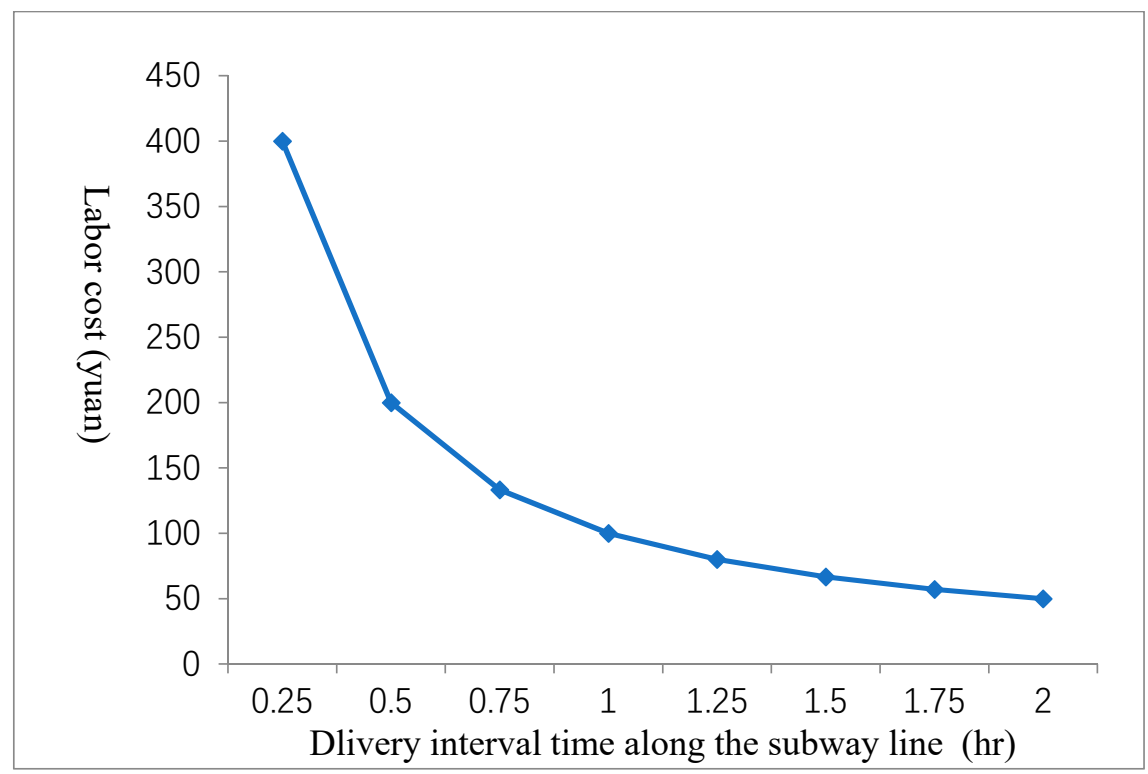

Figure 11. Relationship between the labor cost and the delivery interval time along the subway line.

(3) Influence of changes in the client time window

In this analysis, we assumed the same number of vehicles and the same delivery frequency along the subway line as in the previous analysis, but also assumed that the earliest sending time and the latest receive time did not change, but that the latest sending time changed. We changed the latest sending time by standardizing the sending time interval. For example, if we assumed that the earliest sending time was 09:00, and the pickup window was $2 \mathrm{~h}$, the sending time window became (09:00-11:00). If the pickup window increased to $3 \mathrm{~h}$, the sending time window became (09:00-12:00). This window reflects the courier company's actual commitment to respond to sender clients.

By simultaneously examining the effects of these variables, we found that under conditions of 20 senders, 20 receivers, one collection hub, one distribution hub, and six vehicles, when the sending time window is less than one hour, the total delivery time and total time outside the delivery time window are very high (Figure 12). This means that when the response time set by the courier company is too short, it will increase the burden on the courier company, leading to low overall delivery efficiency. In contrast, widening the sending time window gradually decreases the total delivery time and the total time outside time window. When the sending time window exceeds a certain threshold value (about $3 \mathrm{~h}$ ), the total delivery time and the total time outside the time window only change a little, which indicates that the response time set by the company is too long, and that the delivery efficiency does not improve. When the sending time window is within 3 to $4 \mathrm{~h}$, the overall delivery efficiency is highest, that is, when the courier company's commitment to pick up the goods is within 3 to $4 \mathrm{~h}$, this maximizes the benefits for the courier company. The quantitative case study creates a model of 20 senders, 20 receivers, one collection hub, one distribution hub, and six vehicles. If the courier company wants to maximize its benefits, it should commit to picking up the goods within 3 to $4 \mathrm{~h}$. 


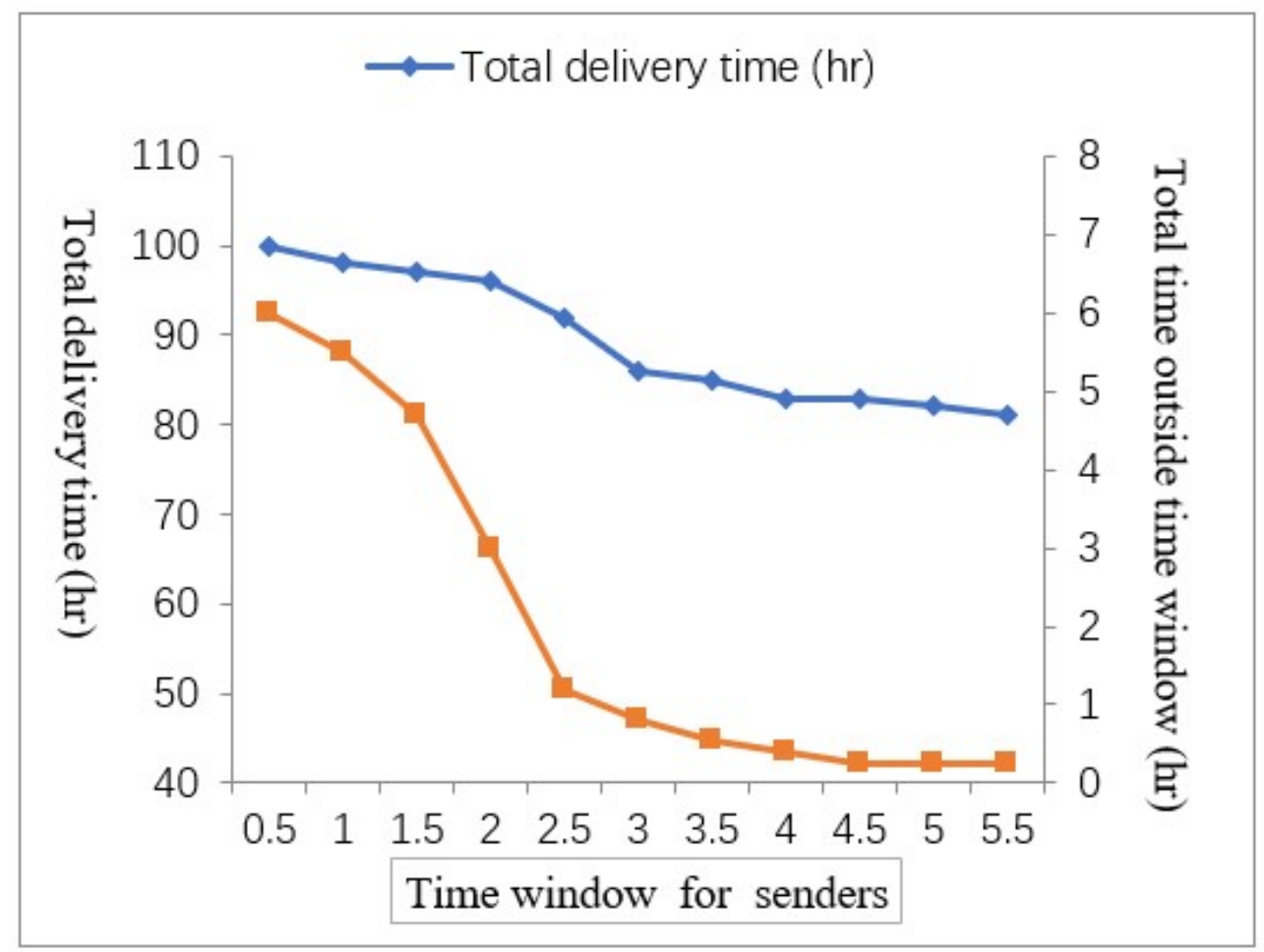

Figure 12. Influence of the time window for senders on the total delivery time and the total time outside the time window.

\section{Conclusions}

In this paper, we studied POM of an intra-city express service (pickup and delivery times) in combination with subway system and ground transportation. We divided the delivery process into three phases (pickup and transport to a collection hub via conventional surface transport, subway transport to a distribution hub, and delivery to the recipient via conventional surface transport). We then established a POM that minimized the total delivery time and designed the corresponding solving algorithm. We applied this model to an empirical case study of a real courier company in Shanghai, China. The optimal delivery path of the case is determined. Meanwhile, according to the actual problem encountered in the delivery of courier companies, based on the basic scenario, the corresponding solution of the four different scenarios of the model were carried out. Then, based on the basic scenario, we further studied the influence of changes in the number of vehicles, delivery frequency along the subway line, and client time windows on the total delivery time, client time window satisfaction, and courier company cost. We found that increasing the number of vehicles decreased the total delivery time and total time outside the time window, but also increased the company cost. With an increase in the delivery frequency along the subway line, the total delivery time and the total time outside the time window both decreased. With a wider sender's time window, the total delivery time and total time outside the time window both decreased, and when the sender's time window increased beyond a certain threshold, the total delivery time and total time outside the time window no longer decreased greatly. In addition to the above conclusions, some strategies and suggestions are put forward for courier companies under specific conditions. For example, under specific conditions, if a courier company wants to reduce the total delivery time and the total time outside of the time window, it can use six vehicles to finish all intra-city express deliveries; under specific conditions, if a courier company wants to balance the overall delivery time and cost, it can use the delivery interval time of one hour in line with the subway line's train frequency; and if the courier company wants to maximize its benefits, it should commit to picking up the goods within 3 to $4 \mathrm{~h}$. 
Our model assumes that a courier traveling along an optimal path is only responsible for either pickup or distribution of the package. In reality, couriers are likely to perform both functions, thus the path optimization problem of combined pickup and distribution needs further research. Environmental factors were not modeled in this study, but most subways use electricity for propulsion, which means that the energy consumption and pollutant emission of subway per transported unit $(\mathrm{t}-\mathrm{km})$ of freight is likely to be less than that of road transportation. Our model helps courier companies to switch from road to subway transportation, which will result in fewer emissions. Future models of path optimization model should consider environmental concerns and the impact on the subway network.

Author Contributions: L.J.Z. designed the paper framework and research questions, and coordinated the research activities for reaching the proposed objectives of this study; X.L.W. conducted the primary research and analytical tasks; X.L.W. and J.S. wrote and edited the paper; Y.S. and H.Y.L. collected and analyzed the data; Q.M.H. and M.C.L. provided valuable research insights into the analysis.

Funding: This research study is supported by grants from the China Postdoctoral Science Foundation Project (No. 2018M642031), the National Natural Science Youth Foundation of China (No. 71503163), the Shanghai Technological Innovation Project (Nos. 17DZ1203300, 17DZ1203302), Shanghai Pujiang Program (No. 14PJC060) and the Humanities and Social Sciences of the Ministry of Education Project (No. 17YJC630146).

Acknowledgments: The authors would like to thank the anonymous reviewers of this journal. We thank the courier company for providing their confidential data for use in our analysis.

Conflicts of Interest: The authors declare no conflict of interest.

\section{References}

1. He, K.; Shao, J.; Liu, Y.; Dong, S. Conceptual design of rail transit based urban logistics delivery system. In Proceedings of the 2008 6th IEEE International Conference on Industrial Informatics, Daejeon, Korea, 13-16 July 2008; pp. 221-226.

2. Yang, J.; Guo, J.; Ma, S. Low-carbon city logistics distribution network design with resource deployment. J. Clean. Prod. 2013, 119, 223-228. [CrossRef]

3. Savelsbergh, M.; Woensel, T.V. City logistics: Challenges and opportunities. Transp. Sci. 2016, 50, 579-590. [CrossRef]

4. Fan, Y.V.; Perry, S.; Klemeš, J.J.; Lee, C.T. A review on air emissions assessment: Transportation. J. Clean. Prod. 2018, 194, 673-684. [CrossRef]

5. Barceló, J.; Grzybowska, H.; Pardo, S. Vehicle routing and scheduling models, simulation and city logistics. In Dynamic Fleet Management; Springer: Boston, MA, USA, 2007; pp. 163-195.

6. Kikuta, J.; Ito, T.; Tomiyama, I.; Yamamoto, S.; Yamada, T. New subway-integrated city logistics system. Procedia Soc. Behav. Sci. 2012, 39, 476-489. [CrossRef]

7. Egbunike, O.N.; Potter, A.T. Are freight pipelines a pipedream? A critical review of the UK and European perspective. J. Transp. Geogr. 2011, 19, 499-508. [CrossRef]

8. Eiichi, T.; Ryutaro, O.; Tatuo, K. Development and future perspectives for underground freight transport systems in Japan. In Proceedings of the 2nd International Symposium on Underground Freight Transportation by Capsule Pipelines and Other Tube/Tunnel Systems, Delft, The Netherlands, 10-12 September 2000.

9. Pielage, B.J. Underground Freight Transportation. A new development for automated freight transportation systems in the Netherlands. In Proceedings of the 2001 IEEE Intelligent Transportation Systems, Oakland, CA, USA, 25-29 August 2001; pp. 762-767.

10. Sinfield, J.V.; Einstein, H.H. Tunnel construction costs for tube transportation systems. J. Constr. Eng. Manag. 1998, 124, 48-57. [CrossRef]

11. Stein, D.; Schoesser, B. CargoCap-Transportation of goods through underground pipelines: Research project in Germany. In Proceedings of the Pipeline Engineering and Construction International Conference, Baltimore, MD, USA, 13-16 July 2003; pp. 1625-1634.

12. Roop, S.S.; Roco, C.E.; Morgan, C.A.; Olson, L.E.; Warner, J.E.; Kang, D.H. Year 4 Report on the Technical and Economic Feasibility of a Freight Pipeline System in Texas; Texas Transportation Institute: College Station, TX, USA, 2003. 
13. Liu, H. Feasibility of using pneumatic capsule pipelines in New York City for underground freight transport. In Proceedings of the Pipeline Division Specialty Congress 2004, San Diego, CA, USA, 1-4 August 2004; p. 146.

14. Qian, Q.H. Build Underground Expressways and Underground Logistics Systems in Megacities—A New Approach to Solving Traffic Problems in China's Megacities; Selected Papers of Academician Qian Q H; Chinese Society of Rock Mechanics and Engineering: Beijing, China, 2007; pp. 3-6. (In Chinese)

15. Dampier, A.; Marinov, M. A study of the feasibility and potential implementation of metro-based freight transportation in Newcastle upon Tyne. Urban Rail Transit 2015, 1, 164-182. [CrossRef]

16. Marinov, M.; Giubilei, F.; Gerhardt, M.; Özkan, T.; Stergiou, E.; Papadopol, M.; Cabecinha, L. Urban freight movement by rail. J. Transp. Lit. 2013, 7, 87-116. [CrossRef]

17. Liao, L.J. Postal development bank express service discussion. Stud. Posts 2006, 22, 19-21. (In Chinese)

18. He, K.; Liu, Y.; Li, S. Necessity and feasibility of rail transit based on city logistics in Beijing. In Proceedings of the IEEE Conference on Industrial Electronics and Applications, Xi'an, China, 25-27 May 2009; pp. 897-901. (In Chinese)

19. Song, J.; Cui, Y. A city express delivery model based on improved genetic algorithm. Comput. Technol. Appl. 2014, 40, 136-139. (In Chinese)

20. Guo, D.T.; Lu, S.J.; Liu, S.Y.; Yang, L.T. Optimizing path of logistics based on multi-level ant colony algorithm. Inf. Technol. 2017, 6, 83-87. (In Chinese)

21. Dantzig, G.B.; Ramser, J.H. The truck dispatching problem. Manag. Sci. 1959, 6, 80-91. [CrossRef]

22. Balinski, M.L.; Quandt, R.E. On an integer program for a delivery problem. Oper. Res. 1964, 12, 300-304. [CrossRef]

23. Clarke, G.; Wright, J.W. Scheduling of vehicles from a central depot to a number of delivery points. Oper. Res. 1964, 12, 568-581. [CrossRef]

24. Eilon, S.; Watson-Gandy, C.D.T.; Christonfides, N. Distribution management-mathematical modelling and practical analysis. IEEE Trans. Syst. Manand Cybern. 1971, 4, 589. [CrossRef]

25. Laporte, G.; Mercure, H.; Nobert, Y. An exact algorithm for the asymmetrical capacitated vehicle routing problem. Networks 1986, 16, 33-46. [CrossRef]

26. Perboli, G.; Tadei, R.; Vigo, D. The Two-Echelon Capacitated Vehicle Routing Problem: Models and math-based heuristics. Transp. Sci. 2011, 45, 364-380. [CrossRef]

27. Vidal, L.; Crainic, Y.G.; Gendreau, M. A hybrid genetic algorithm with adaptive diversity management for a large class of vehicle routing problems with time-windows. Comput. Oper. Res. 2013, 40, 475-489. [CrossRef]

28. Hou, Y.M.; Jia, Z.H.; Tian, X.; Wei, F.F. Research on the optimization on the vehicle logistical distribution with soft time windows. J. Syst. Eng. 2015, 2, 240-250. (In Chinese)

29. Ghilas, V.; Demir, E.; Van Woensel, T. An adaptive large neighborhood search heuristic for the pickup and delivery problem with time windows and scheduled lines. Comput. Oper. Res. 2016, 72, 12-30. [CrossRef]

30. Wei, X.J.; Yuan, J.; Wang, W.; Zhou, J. VRP model with time threshold and competitive decision algorithm. Comput. Eng. Des. 2018, 39, 266-270. (In Chinese)

31. Zhao, L.J.; Li, H.Y.; Li, M.C.; Sun, Y.; Hu, Q.; Mao, S.; Li, J.; Xue, J. Location selection of intra-city distribution hubs in the metro-integrated logistics system. Tunn. Undergr. Space Technol. 2018, 80, 246-256. [CrossRef]

(C) 2019 by the authors. Licensee MDPI, Basel, Switzerland. This article is an open access article distributed under the terms and conditions of the Creative Commons Attribution (CC BY) license (http://creativecommons.org/licenses/by/4.0/). 